\title{
Analysts' stock recommendations, earnings growth and risk
}

\author{
Kenneth Peasnell \\ Department of Accounting and Finance \\ Lancaster University Management School \\ Bailrigg, Lancaster, LA1 4YX \\ United Kingdom \\ Email: k.peasnell@lancaster.ac.uk \\ Yuan Yin (Contact Author) \\ Department of Accountancy \\ College of Business Administration \\ California State University, Long Beach \\ 1250 Bellflower Boulevard, Long Beach, California 90840 \\ United States \\ Tel: +1 5629854831 \\ Fax: +1 5629857586 \\ Email: yuan.yin@csulb.edu \\ Martien Lubberink \\ School of Accounting and Commercial Law \\ Victoria University of Wellington \\ Wellington, New Zealand 6140 \\ martien.lubberink@vuw.ac.nz
}

We thank the editor, Anne Wyatt, and the anonymous reviewer for their detailed comments and suggestions. We also thank Steve Young, Herb Hunt, and seminar participants at Lancaster University Management School, the University of Amsterdam and the 2009 American Accounting Association Western Regional Meeting for their helpful comments. The usual disclaimer applies. 


\title{
Analysts' stock recommendations, earnings growth and risk
}

\begin{abstract}
A key output of sell-side analysts is their recommendations to investors as to whether they should, buy, hold or sell a company's shares. However, relatively little is known regarding the determinants of those recommendations. This paper considers this question, presenting results that suggest that recommendations are dependent on analysts' short-term and long-term earnings growth forecasts, as well as on proxies for the analysts' unobservable views on earnings growth in the more distant future and risk. Furthermore, analysts who appear to incorporate earnings growth beyond the long-term growth forecast horizons and risk into their recommendation decisions make more profitable stock recommendations.
\end{abstract}




\section{Introduction}

Sell-side analysts are important information intermediaries in the capital market. Over the past four decades, a staggering number of published academic studies - more than five hundred to date - have examined the properties of analysts' earnings per share forecasts (for useful reviews, see, e.g., Brown, 2000; Ramnath et al., 2008a, 2008b; Bradshaw, 2011). However, Schipper (1991) notes that earnings forecasts are just one output of sellside research; she calls for more study of how analysts reach their final judgments, expressed in the form of buy-sell-hold stock recommendations.

Some limited progress has been made in the two decades that have passed since Schipper (1991) reached this conclusion (Ramnath et al., 2008a; Bradshaw, 2011; Brown et al., 2015). However, much still remains to be done. One difficulty that researchers face is that the work analysts perform is unobservable. Nevertheless, as Bradshaw (2011) notes, we have reached a point where some penetration of the "black box" is required in order to develop deeper insights. He suggests that a potentially useful approach would be to simultaneously examine analysts' multiple summary outputs. This is the focus of the present paper.

We build on the prior literature within the context of a valuation framework. This provides a structured approach to think about the linkages between the forecasts and stock recommendations carried out by analysts. We predict that analysts’ stock recommendations are positively associated with their forecasts of earnings growth in the short-term and in the medium-term. We also predict that analysts’ stock recommendations will be positively influenced by their expectations of earnings growth in the more distant future, and be negatively associated with their views on risk, neither of which can be directly conveyed by analysts to investors in simple but credible metrics. 
To test these predictions, we examine the relationships between analysts’ stock recommendations and (1) their short-term earnings growth and long-term growth forecasts, (2) proxies designed to capture their expectations about earnings growth beyond their long-term growth forecast horizons, and (3) risk metrics employed to proxy for analysts’ risk assessments. Our study uses U.S. data covering the 1995-2012 period. We believe this paper is among the first to provide empirical evidence that analysts’ long-term growth forecasts appear to incorporate the tendency of profitability to revert to the mean over time. We find that, all else being equal, firms with higher short-term earnings growth forecasts receive more favourable stock recommendations. Consistent with Bradshaw (2004), we show that the relationship between stock recommendations and long-term growth forecasts is positive, but in addition we show that the relationship is non-linear and declining, reflecting the valuation implication of profitability being mean-reverting. We also show that above-mean (below-mean) profitability has positive (negative) but diminishing effects on stock recommendations. We find that stock price volatility is negatively associated with stock recommendations. In contrast, market beta appears to enter analysts’ recommendation decisions primarily through its adverse mediating effect on the sensitivity of recommendations to long-term growth forecasts.

Bradshaw (2004) suggests that the relationship between analysts’ long-term growth forecasts and recommendations has a negative impact on the value of their stock recommendations. ${ }^{1}$ This conclusion is based on Bradshaw’s (2004) evidence that long-

\footnotetext{
1 Previous studies have shown that recommendation revisions and levels of individual recommendations (when "hold" recommendations are treated as "sell" recommendations) are associated with future returns (e.g., Stickel, 1995; Womack, 1996; Jegadeesh et al., 2004; Ertimur et al., 2007). Bradshaw (2004), however, finds that consensus recommendations are not associated with abnormal returns. In our view, levels of consensus recommendations are more likely subject to distortions caused by analysts' conflict of interests than recommendation revisions, and thus might not be best suited for assessing the value of recommendations.
} 
term growth forecasts are negatively associated with future stock returns. In contrast, Jung et al. (2012) show that the market appears to view long-term growth forecasts as informative, and reacts more strongly to recommendation revisions that are accompanied by long-term growth forecasts. Motivated by this line of inquiry, we also investigate whether analysts' incorporation of expectations about earnings growth beyond their longterm growth forecast horizons and their incorporation of risk is associated with the profitability of their stock recommendations. Our empirical analysis suggests that analysts who are employed by large brokerage firms and who follow less industries and have higher forecast accuracy and more firm-specific experience are more likely to incorporate earnings growth beyond long-term growth forecast horizons in making recommendations. We find that abnormal returns of stock recommendations issued by analysts who appear to take into account earnings growth beyond their long-term growth forecast horizons and risk are significantly higher than those of other analysts. Additional empirical analyses also suggest that our proxies for analysts' expectations about earnings growth beyond their long-term growth forecast horizons predict the realized actual earnings growth rates in the next ten years, and that the stock market appears to price the proxies in a way that is consistent with how they are linked to analyst recommendations.

This study contributes to the literature in several ways. First, it extends and complements previous studies that attempt to explain analysts’ recommendation decisions (e.g., Block, 1999; Bradshaw, 2002, 2004; Brown et al., 2015). Bradshaw (2004) documents a positive relationship between analysts' stock recommendations and long-term growth forecasts using a parsimonious empirical specification as a first pass to look at the issue. We build on this work by presenting results that suggest that stock recommendations are also dependent on analysts’ short-term earnings growth forecasts 
and their expectations about earnings growth in the more distant future, as well as of their views about risk. Second, this study contributes proxies for constructs that are already in the models of analysts’ decisions but cannot be conveyed by analysts to investors in a simple and credible metric. Third, we extend previous studies (e.g., Ertimur et al., 2007; Jung et al., 2012) that examine the relationship between analyst earnings and long-term growth forecasts and the economic value of their recommendations. We present results that suggest that analysts' incorporation of risk and expectations about earnings growth beyond long-term growth forecast horizons is associated with their providing more profitable recommendations. Not only do these findings enhance our understanding of analysts’ recommendation decisions, they also have the potential to assist investors in identifying which recommendations are likely to signal positive returns and which will not.

The remainder of this study is organized as follows. Section 2 develops our theoretical framework and predictions, and describes our research design. Section 3 outlines our sampling procedure and data, and provides descriptive statistics. Section 4 reports results and presents our investigation of the effect of incorporation of risk and long-run earnings growth on recommendation profitability, while section 5 summarizes and concludes.

\section{Theoretical framework and research design}

\subsection{Outputs of sell-side analysts}

Sell-side analysts are important information intermediaries in the capital market. In addition to providing detailed comments and discussions of the prospects of companies and industries they follow, analysts generally provide three summary outputs of their 
work: (1) a short-term earnings per share (EPS) forecast; (2) a forecast of growth in expected EPS, typically over a three-to-five year horizon; and (3) a recommendation to investors to buy, hold, or sell the stock. ${ }^{2}$ While the first one has been extensively studied by accounting researchers, the last two have received much less attention.

A useful way of thinking about such recommendations and earnings forecasts is by reference to an accounting-based pricing equation of the sort developed by Ohlson and Juettner-Nauroth (2005). Ohlson and Juettner-Nauroth (2005) show that the economic value of an equity security at date $t=0$ is equal to the capitalized next-period (FY1) expected earnings per share, eps 1 , plus the present value of capitalized abnormal growth in expected eps in all future periods:

$$
\hat{P}_{0}=\frac{e p s_{1}}{r}+\sum_{t=1}^{\infty} R^{-t}\left\{\frac{\text { aeps }}{r}\right\}
$$

where: $\hat{P}_{0}$ can be thought of as the analyst's view of how much the stock is really worth (which may differ from the current share price, $P_{0}$ ); $r$ is the cost of capital and $R=1+$ $r$; and aeps $_{t+1}=e p s_{t+1}-\left[e p s_{t}(1+r)-r \cdot d p s_{t}\right]$ is the abnormal earnings growth, defined as the change in EPS adjusted for the cost of capital and dividends $\left(d p s_{t}\right)$. To relate Equation (1a) to the earnings forecasts reported by analysts, it is helpful to break the stream of future payoffs into three sets, as follows:

\footnotetext{
${ }^{2}$ It is also commonplace for analysts to provide a so-called "target price," which is their prediction of the share price in the future (usually one year hence). We do not consider this metric further here as it is logically a function of the analyst's predictions of a firm's future performance. The central focus of this paper is the relationship between recommendations and earnings growth forecasts. Target price can be influenced by factors that fall outside the scope of this study, such as expectations of interest rate changes. Moreover, using target price as a proxy for expected price would shift the focus away from the relationship between recommendations and the earnings and earnings growth forecasts, which are the central outputs of the analyst's work and the primary concern of this paper.
} 


$$
\hat{P}_{0}=\frac{e p s_{1}}{r}+\sum_{t=1}^{4} R^{-t}\left(\frac{\text { aeps }_{t+1}}{r}\right)+\sum_{t=5}^{\infty} R^{-t}\left(\frac{\text { aeps }_{t+1}}{r}\right)
$$

For expositional purposes, assume that aeps grows at a constant compound rate $g_{1}$ during the medium term (years 3-5), i.e., $a e p s_{t+1}=a e p s_{t}\left(1+g_{1}\right), t=2, \ldots, 4$, and at $g_{2}$ thereafter. Assuming $g_{2}<r$, we can simplify (1b), as follows:

$$
\hat{P}_{0}=\frac{e p s_{1}}{r}+\frac{\text { aeps }_{2}}{r}\left[\frac{1-\left(\frac{1+g_{1}}{1+r}\right)^{4}}{r-g_{1}}\right]+\left(\frac{\operatorname{aeps}_{2}\left(1+g_{1}\right)^{4}}{r(1+r)^{5}}\right)\left[\frac{1}{r-g_{2}}\right] \text {. }
$$

This provides the framework for thinking about the outputs of financial analysts.

The analyst provides two measures of future earnings: a forecast of one-year-ahead earnings per share, $e s_{1}$, and a forecast of what is conventionally but somewhat misleadingly referred to as "long-term" (really medium-term) growth in earnings, LTG, where eps $s_{t+1}=e p s_{t}(1+L T G), t=1,2, \ldots, 4$. From this, we could infer that the rate of growth, $g_{1}$, in abnormal earnings over this interval (together with the discount rate, $r$ ) will enable the analyst to arrive at an estimate of the second term on the right-hand side of Equation (1b). If a firm pays out all its medium-term earnings as dividends, abnormal earnings growth during this period will be reduced to $a e p s_{t+1}=e p s_{t+1}-e p s_{t}$, and $g_{1}=L T G$. However, to complete the valuation exercise represented by Equation (2), the investor must also estimate $g_{2}$, the growth rate of aeps in the more distant future, and this cannot be discerned from the analyst's published outputs. In what follows, we follow conventional market practices here and define what is really medium-term earnings growth as long-term growth (LTG), and define the unobservable "really-long-term growth” in eps as $g_{2}=R L T G$. 
Within this framework, we can treat $\hat{P}_{0}$ as a representation of the (unobservable) view the analyst has of how much the stock is worth, and the analyst's recommendation $(R E C)$ as a function of the difference between this unobservable amount and the stock's current price $P_{0}$. We can also treat $\hat{P}_{\mathbf{0}}$ as dependent on (1) the analyst's observable forecasts of $e p s_{1}$ and $L T G$, (2) the unobservable $R L T G$, and (3) the discount rate for the stock, the principal determinant of which is the analyst's (also unobservable) views on risk (RISK). Putting these together, we get:

$$
\begin{aligned}
R E C & =f\left(\hat{P}_{0}-P_{0}\right) \\
& =g\left(e^{e p s_{1}}, L T G, R L T G, \text { RISK }\right) .
\end{aligned}
$$

Logically, analysts ought to make a buy recommendation when intrinsic value is sufficiently larger than current price to justify the transaction costs involved (i.e., $\hat{P}_{0} \gg$ $\left.P_{0}\right)$, and vice versa when the reverse condition holds $\left(\hat{P}_{0} \ll P_{0}\right)$. Being dependent on $\hat{P}_{0}-P_{0}, R E C$ therefore ought to depend on the extent to which analysts think their beliefs regarding eps $s_{1}, L T G, R L T G$, and $R I S K$, are at variance with those embedded in current prices.

However, analysts’ views are not observable. Hence we formulate the reduced form of (3) in terms of the analysts' beliefs concerning the levels of these variables, i.e., as $R E C=g\left(e^{e p s_{1}}, L T G, R L T G, R I S K\right)$. We use this framework to explore the relationship between analysts' stock recommendations and their forecasts of earnings ( $e p s_{1}$ and LTG), and how these relationships can be affected by their beliefs about RLTG and RISK. Because we are unable to identify the direction or extent to which our observable measures eps $s_{1}$, LTG, RISK and our proxies for $R L T G$ differ from current market beliefs, 
classification errors will result. This will reduce the power of our tests to detect relationships between $R E C$ and these measures. ${ }^{3}$

A starting point for our investigation is Bradshaw (2004) who examines how analysts use their earnings forecasts to generate stock recommendations. The author analyzes the associations between stock recommendations and value estimates derived from the residual income model and practical valuation heuristics using analysts’ earnings forecasts. He finds that $L T G$ better explains the cross-sectional variation in analysts' stock recommendations compared to residual income value estimates.

Bradshaw’s (2004) empirical specification is parsimonious in that it involves regressing $R E C$ on $L T G$ alone, and does not consider eps $s_{1}$. However, our framework, and the huge amount of attention given to eps in the financial press (Brown, 1993), suggests it is an important additional analyst output, and one therefore likely to be an important determinant of their recommendations. Bradshaw’s (2004) empirical specification implicitly assumes that $L T G$ will persist indefinitely, and thus no account need be taken of RLTG (i.e., of the analysts' unobservable views of the more distant future), or of RISK (their assessments of how risk should affect share valuations). Previous studies (e.g., La Porta, 1996; Dechow and Sloan, 1997) that examine the relationship between earnings expectations and stock returns have also used analysts’ LTG forecasts to proxy for investors’ expectations about earnings growth in all future years without explicitly considering the likely declining persistence of $L T G$.

\footnotetext{
3 The rationale for this reduced-form expression is that cross-sectional differences in earnings forecasts will reflect differences in the extent to which forecasts have been revised (the further a forecast is away from the mean, the more likely it is to be the result of a forecast revision). This seems plausible, given that our focus is on consensus (rather than individual) recommendations and earnings forecasts.
} 
To advance our understanding of the role of analysts’ earnings growth expectations in their stock recommendation decisions, we analyze the effects of the short-term earnings growth rate (i.e., the proportionate increase in forecast eps $_{1}$ over the reported earnings per share of the previous fiscal year, eps 0 ), $L T G$, and proxies designed to capture the extent to which the latent variable $R L T G$ differs from $L T G$.

There are good reasons to believe that earnings growth rates change over time. Standard economic arguments suggest that profitability is mean-reverting under competitive conditions: entrepreneurs seek to enter profitable industries and exit less profitable ones (e.g., Stigler, 1963). This prediction is consistent with the evidence (e.g., Brooks and Buckmaster, 1976; Freeman et al., 1982; Fama and French, 2000). Based on these arguments, we make two predictions:

1. REC is a positive but diminishing function of LTG: $\partial R E C / \partial L T G>0$ and $\partial^{2} R E C / \partial L T G^{2}<0$

2. Above-mean (below-mean) past profitability will have a positive (negative) but diminishing effect on $R E C$.

The first prediction reflects the attenuating effect the unobservable latent variable $R L T G$ is expected to have on the analyst's estimation of intrinsic value, $\hat{P}_{0}$, and hence on $R E C$. In our design, $R L T G$ plays the role of a correlated omitted variable. We address this problem in our experimental design in two ways: by modifying our expectations concerning the relationship between $R E C$ and $L T G$, and by incorporating profitability mean reversion into the design.

If we hold all else equal, economic theory predicts that the risk-aversion of investors will result in high-risk companies having lower equity prices than low-risk ones. Not only 
will high predicted earnings growth attract competition, it will often be dependent on high-risk investments in $\mathrm{R} \& \mathrm{D}$ and other intangibles. We therefore predict that $R E C$ will be a negative function of RISK: $\partial R E C / \partial R I S K<0$.

\subsection{Research design}

We use a quadratic model of $L T G, R E C=g\left(L T G, L T G_{2} \ldots\right)$ to test for the predicted attenuating effect of the correlated omitted variable $R L T G$ on the analyst's estimation of

intrinsic value, $\hat{P}_{0}$, and hence on $R E C$. We predict $R E C$ will be positively associated with $L T G$ and negatively associated with $L T G^{2}$, because the higher $L T G$ is, the greater the potential deviation between $R L T G$ and $L T G$ and the less weight the analysts will place on $L T G$ in estimating $\hat{P}_{0}$. To reflect the possibility that analysts respond differently to the mean reversion of losses and profits we also use an alternative model including two interaction variables between $L T G$ and indicator variables representing the bottom and top $L T G$ quartiles, respectively, to examine the relationship between $L T G$ and recommendations.

We allow for the previously documented fact that the reversion of profitability to its mean can take a very long time (e.g., Fairfield et al., 2009). The extent to which profitability deviates from its mean signals expected changes in profitability and earnings growth in the long run. Hence, we use this deviation to construct proxies for the latent variable, RLTG. We follow Fama and French (2000) both in our estimation of the mean of profitability and in how profitability reverts to its mean. We then examine the effects of the latent variable $R L T G$ on stock recommendations using measures representing both the magnitude and direction of the deviations of profitability from its mean. We predict 
that analysts are likely to think favourably of firms with high past profitability, and their recommendations are likely affected by their expectations about how profitability will change in the long run. We predict above-mean (below-mean) past profitability will have a positive (negative) but diminishing effect on $R E C$.

We define profitability in terms of return on equity ( $R O E)$, as analysts' work focuses on equities. We first estimate a cross-sectional regression model of the return on equity that closely resembles the one used by Fama and French (2000). We then use the coefficient estimates to compute the expected value of return on equity ( $E(R O E)$ ), i.e., a proxy for the mean of profitability, for a given firm:

$$
R O E=d_{0}+d_{1} B M+d_{2} D D+d_{3} P A Y O U T+d_{4} L o g M V+d_{5} R D+d_{6} L E V E R A G E+\varepsilon
$$

where: $B M$ is the ratio of book equity to the market value of equity at the end of period $t$; $D D$ is equal to 1 if the firm issues dividends during the period, and 0 otherwise; PAYOUT is the dividend payout ratio; $\log M V$ is the natural log of market value; $R \& D$ is the ratio of research and development expenses to net sales; and LEVERAGE is the ratio of total liabilities to total assets. The explanatory variables in Equation (4) are chosen on the basis that: (1) book-to-market captures expected future firm profitability, (2) firms paying dividends tend to be much more profitable than those that do not pay any (Fama and French, 1999; Choi et al., 2011), (3) firms tend to relate dividends to recurring earnings, and the distribution of dividends thus conveys information about expected future earnings (Miller and Modigliani, 1961), (4) large firms tend to have higher and more stable profitability than small firms, (5) R\&D investments affect earnings negatively in the near term, but foster future growth in earnings, and (6) financing activities raise funds for expansion and growth, and leverage affects the ROE denominator. 
For each firm-month observation, we compute the deviation of past $R O E$ from its expected value (hereafter, $D F E$ ) by taking the difference between $R O E$ in the previous year and its expected value, $E(R O E): D F E_{t}=R O E_{t-1}-E\left(R O E_{t-1}\right)$. Let $N D F E$ denote $D F E_{t}<0$ and PDFE denote $D F E_{t}>0$. Fama and French (2000) find that the speed of mean reversion is faster when return on assets is below its expected value, and when it is further from the expected value in either direction. They use the squared values of NDFE and PDFE to measure the magnitude to which profitability is below and above its expected value, respectively. For the purpose of modelling the diminishing effect of above-mean (below-mean) past profitability on REC, the squared values of NDFE and $P D F E$ are computed and denoted as SNDFE and SPDFE, respectively. We predict $R E C$ will be positively associated with PDFE, NDFE, and SNDFE, and negatively associated with SPDFE.

Before testing our predictions, we carry out an exploratory analysis to see whether analysts appear to incorporate mean reversion in profitability when forecasting LTG. Fama and French (2000) analyze the impact of profitability mean reversion on future earnings by regressing changes in reported earnings on measures that capture the magnitude and direction of deviations of profitability from its mean. We use their regression specification, simply substituting $L T G$ for changes in reported earnings, the dependent variable in their model:

$$
L T G=\alpha+b_{1} D F E+b_{2} N D F E+b_{3} S N D F E+b_{4} S P D F E+\varepsilon
$$

Based on Fama and French's (2000) work, we make the following predictions concerning $b_{1}<0, b_{2}<0, b_{3}>0, b_{4}<0$. 
Existing evidence on how analysts make allowances for risk is scarce. One possibility is that analysts adjust for the risk of equity by discounting future payoffs using a discount factor based on the Capital Asset Pricing Model (Sharpe, 1964; Lintner, 1965) (CAPM), an approach emphasized in standard valuation textbooks. Prior research, however, suggests that analysts tend to mainly rely on valuation multiples instead of present value models, and that they are concerned about risk in a firm-specific sense rather than in terms of its marginal impact on a well-diversified portfolio (e.g., Barker, 1999; Block, 1999). This raises the possibility that analysts do not adjust for risk by using a discount factor based on a formal pricing model such as the CAPM. Consistent with Kecskes et al. (2011), our own reading of brokers' reports suggests that risk is generally defined by reference to firm-specific operational and business risks, and uncertainties concerning macroeconomic factors that potentially affect a firm's future earnings. It is difficult, if not impossible, to construct a quantitative measure of analysts’ risk assessments by codifying such qualitative discussions. At any rate, no such metric is currently available. Moreover, to our best knowledge, few brokerage houses generate quantitative risk forecasts, and no such data are available from any data vendor. Hence, instead of examining how analysts' (unobservable) risk assessments affect their stock recommendations, we step back and ask a different question: To what extent do analysts take into account traditional risk measures in making stock recommendations?

We mainly consider two traditional risk measures, market beta and stock price volatility. The CAPM assumes that only systematic risk (market beta) is priced. However, it has been demonstrated theoretically that in a market with incomplete information and transaction costs, rational investors price idiosyncratic risk (Merton, 1987) and there is evidence that idiosyncratic risk does indeed play a role in explaining 
the cross-section of average stock returns (Malkiel and Xu, 1997, 2006). Furthermore, sell-side analysts specialize by industry and usually follow a limited number of stocks (Boni and Womack, 2006), suggesting that they might not take full account of the big (diversification) picture when recommending individual stocks.

Fama and French (1992) argue that the risk of a stock is also a function of firm size and book-to-market. Behavioural studies (e.g., La Porta, 1996; Dechow and Sloan, 1997) argue that the book-to-market factor in returns is the result of market participants systematically overestimating (underestimating) the growth prospects of growth (value) firms. We do not address why size and book-to-market may affect returns, but simply include them as controls.

We also examine the potential interactions between risk and growth. The future earnings of high beta firms are likely to be more sensitive to changes in the overall economy. We predict that analysts are able to capture this earnings implication of market beta and discount the $L T G$ forecasts of high beta firms when making recommendations. Meanwhile, for a firm with high growth but also a high degree of risk, analysts are likely to issue a less favourable recommendation. We allow for such possible interaction between $L T G$ and market beta and stock price volatility in our empirical analysis.

We compute the analyst's short-term earnings growth forecast (hereafter, $S G$ ) using the formula: $S G=\left(E P S_{1}-E P S_{0}\right) / E P S_{0} . E P S_{1}$ is one-year-ahead consensus earnings per share forecast, and $E P S_{0}$ is the last reported earnings per share. Because it is difficult to make economic sense of $S G$ when $E P S_{0}<0$, we follow Bradshaw and Sloan (2002) by computing the short-term growth forecast only for observations with positive $E P S_{0}$. We predict $S G$ to be positively associated with stock recommendations. 
Prior research has shown that analysts’ earnings forecasts are optimistically biased, possibly due to analysts' incentives to generate trading, to cultivate management, and to maintain good relationships with underwriting clients of their brokerage firms (e.g., Francis and Philbrick, 1993; Lin and McNichols, 1998; Jackson, 2005; Brown et al., 2015). However, it is possible that the analysts may take into account the optimistic bias in their earnings forecasts when making stock recommendations. We include the signed forecast error of EPS ${ }_{1}$ (Forecast Error) in our empirical specifications to capture this possible element in analysts' recommendation decisions. We predict the coefficient on Forecast Error to be negative, reflecting the analysts' effort to discount the optimistic bias in their earnings forecasts.

We primarily use an ordinary least squares (OLS) regression analysis to test our predictions. Following Bradshaw (2004), Barniv et al. (2009) and He et al. (2013), we use the monthly consensus (mean) stock recommendation as the dependent variable. We use consensus (i.e., average) data, both to facilitate comparison with key prior studies and because there are strong reasons to believe that average measures are likely to better reflect the price setting process in the market. In addition, we also examine our predictions using multinomial ordered logit regression analysis, in which the dependent variable is the quintile ranking of monthly consensus stock recommendation, a 5-point scale discrete variable.

We estimate the following regression to test our predictions:

$$
\begin{aligned}
R E C= & \alpha_{0}+\beta_{1} S G+\beta_{2} L T G+\beta_{3} L T G^{2}+\beta_{4} N D F E+\beta_{5} P D F E+\beta_{6} S N D F E \\
& +\beta_{7} S P D F E+\beta_{8} \text { Forecast Error }+\gamma_{1} \text { Beta }+\gamma_{2} L T G \times \text { Beta } \\
& +\gamma_{3} \text { Volatility }+\gamma_{4} L T G \times \text { Volatility }+\gamma_{5} L o g M V+\gamma_{6} B M \\
& +\sum_{j=1}^{9} \delta_{j} \text { Industry Dummy }+\sum_{i=1995}^{2012} \theta_{i} \text { Yr Dummy }+\varepsilon
\end{aligned}
$$


where: REC represents either the monthly consensus stock recommendation or the quintile ranking of monthly consensus recommendations; $S G$ represents the analyst’s short-term earnings growth forecast; LTG represents the monthly consensus earnings growth forecast for the next three-to-five years; and $L T G^{2}$ represents the square value of LTG; NDFE represents negative deviations of ROE from its mean; PDFE represents positive deviations of ROE from its mean; and SNDFE and SPDFE represent the square of $N D F E$ and $P D F E$, respectively.

Forecast Error is measured by dividing the difference between $\mathrm{EPS}_{1}$ and the actual earnings per share $\left(\mathrm{EPS}_{\mathrm{a}}\right.$ ) by the absolute value of EPS $\mathrm{a}$. Beta is calculated monthly using five years’ monthly stock and market returns; Volatility represents the three-month stock price volatility; $L T G \times$ Beta and $L T G \times$ Volatility represent the interaction variables between LTG and Beta and Volatility, respectively; LogMV represents size as measured by market capitalisation; and $B M$ is the book-to-market ratio. We predict the coefficients on Beta, Volatility, BM, and $L T G \times$ Beta to be negative and the coefficient on $\log M V$ to be positive. We make no prediction with regard to the sign of LTG $\times$ Volatility. The model controls for both year and industry effects by including year indicator variables ( $\mathrm{Yr}$ Dummy) and industry indicator variables (Industry Dummy) formed based on the $1^{\text {st }}$ level Global Industry Classification Standard (GICS) industry classification.

To reflect the fact that the mean reversion of profitability can be up or down, we also analyze the potential effect of the latent variable $R L T G$ on the relationship between $R E C$ and LTG using an alternative model that includes two interaction variables between $L T G$ and indicator variables representing the bottom and the top $L T G$ quartiles respectively. We expect the top (bottom) quartile LTG forecasts to have a weaker (stronger) effect on stock recommendation relative to the other two quartiles of $L T G$ forecasts to reflect that 
high (low) profitability will revert to the mean in the long run. The regression equation we estimate is as follows:

$$
\begin{aligned}
R E C= & \alpha_{0}+\beta_{1} S G+\beta_{2} L T G+\beta_{3} L T G_{-} Q^{1}+\beta_{4} L T G \times L T G \_Q^{1}+\beta_{5} L T G \_Q^{4} \\
& +\beta_{6} L T G \times L T G \_Q^{4}+\beta_{7} N D F E+\beta_{8} \text { PDFE }+\beta_{9} S N D F E+\beta_{10} S P D F E \\
& +\beta_{11} \text { Forecast Error }+\gamma_{1} \text { Beta }+\gamma_{2} L T G \times \text { Beta }+\gamma_{3} \text { Volatility }+\gamma_{4} L T G \times \text { Volatility } \\
& +\gamma_{5} \text { LogMV }+\gamma_{6} B M+\sum_{j=1}^{9} \delta_{j} \text { Industry Dummy }+\sum_{i=1995}^{2012} \theta_{i} \text { Yr Dummy }+\varepsilon
\end{aligned}
$$

where: $R E C$ is monthly consensus stock recommendation; $L T G \_Q^{1}$ is 1 when the LTG forecast falls into the bottom quartile of $L T G$ and 0 otherwise; $L T G \_Q^{4}$ is 1 when $L T G$ belongs to the top quartile of $L T G$ and 0 otherwise; and $L T G \times L T G \_Q^{1}$ and $L T G \times$ $L T G \_Q^{4}$ are interaction variables between $L T G$ and LTG_Q ${ }^{1}$ and $L T G \_Q^{4}$, respectively. We predict the coefficient on $L T G_{-} Q^{1}$ to be negative and that on $L T G_{-} Q^{4}$ to be positive. We expect the coefficient on $L T G \times L T G \_Q^{1}$ to be positive and that on $L T G \times L T G \_Q^{4}$ to be negative.

\section{Sample selection, data and descriptive statistics}

Our sample selection procedures are summarised in Table 1. The analyst data are from the Institutional Brokers’ Estimate System (I/B/E/S). Our sample covers the period January 1995-December 2012. We obtain monthly consensus analyst forecasts including stock recommendations (mean), long-term growth (median), and one-year-ahead earnings per share $\left(\mathrm{EPS}_{1}\right)$ for all U.S. firms listed on the NYSE, the AMEX, and on NASDAQ. I/B/E/S enters reported earnings on the same basis as analysts’ forecasts. To ensure comparability, we use the actual earnings per share (EPS $)_{0}$ from the I/B/E/S detailed actual file for the estimation of $S G$ and $R O E$. During the sample period, I/B/E/S analysts provide both recommendations and $E P S_{1}$ forecasts for 16,877 U.S. firms. LTG forecasts 
are available for approximately $79 \%$ of these firms. We eliminate duplicated monthly observations.

We merge I/B/E/S data with COMPUSTAT data used for the calculation of accounting variables. We require firm-month observations to have positive $E P S_{0}$ and book value per share for the estimation of $S G$ and $R O E$, respectively. We estimate risk variables for firm-month units using firm and stock return data from the Center for Research in Security Prices (CRSP) database. Beta is estimated each month by regressing monthly returns of the stock on monthly market returns over a five-year period.

Volatility $^{4}$ is measured using the annualized standard deviation of daily returns three months preceding the consensus recommendation dates. Definitions of variables used in empirical analysis are detailed in Table 2.

To mitigate the potential influence of outliers, we eliminate $1 \%$ of the lowest and highest tails of all variables except the consensus monthly stock recommendations. The sample we use to analyze whether analysts’ LTG forecasts incorporate the mean reversion in profitability comprises 401,451 firm-month observations, representing 7,023 distinct firms. The sample used for the estimation of the full model of Equation (6a), includes 284,655 firm-month observations and 4,946 distinct firms. Following prior literature, the coding of recommendations is inverted to be $1=$ strong sell, 2=sell, 3=hold, 4=buy and $5=$ strong buy.

Panel A in Table 2 presents descriptive statistics for the main variables that will be used in the subsequent analysis. Both the mean and the median of consensus

\footnotetext{
${ }^{4}$ Volatility $=\sigma[\ln (1-$ daychange $)] \times\left(\frac{365 \times j}{m}\right)^{\frac{1}{2}}$, where $\sigma$ is standard deviation; $j$ represents the number
} of business days in the period; and $m$ represents the number of days in the period. 
recommendation are close to a buy rating (3.782; 3.800), revealing analysts' optimism that has been widely documented in prior literature. The mean and median of $L T G$ are 0.170 and 0.150 , respectively. The mean of $S G$ is 0.192 , higher than mean $L T G$. The average $R O E$ of the sample firms is $8.6 \%$. The mean and median of $D F E$, deviation of $R O E$ from its expected value, are -0.002 and -0.010 , respectively; the mean of negative deviations is -0.027 and that of positive deviations is 0.025 . The mean (median) of market beta and stock price volatility are $1.085(0.973)$ and $0.476(0.409)$, respectively.

Panel B in Table 2 presents the results of Pearson correlation analysis of the main variables used in the subsequent empirical analysis. Stock recommendations are positively correlated with both the short-term and the medium-term earnings growth forecasts and with ROE but are negatively correlated with DFE. Both Beta and Volatility are positively correlated with recommendations. Note that the positive correlation between recommendations and Volatility possibly is caused by year effects (price volatility was extremely high during the two most recent stock market crashes). LTG is negatively correlated with past $R O E$ and its deviation from its expected value DFE. SG is also negatively associated with both $R O E$ and $D F E$. The moderate correlation between Beta and Volatility (0.332) indicates that the information content of the two risk measures is to some degree overlapping; Volatility and Beta are both manifestations of risk. This necessitates the control of each of the pair in the regression tests. The mean of $D D$ was 0.462, indicating that in less than half of the sample firm-years were dividends paid.

Our OLS regression analyses use panel data pooled across firms and multiple periods (months). When the residuals are correlated across observations, OLS standard errors can be biased and the inferences about the coefficient estimates will be inaccurate. Following Petersen (2009), we therefore adjust the standard errors of the regression slopes in our 
regression tests for the possible dependence in residuals by clustering standard errors on firm and month dimensions.

Our sample covers three sub-periods marked by dramatic shifts in the economic conditions in the U.S. as well as important regulatory changes. The first sub-period is 1995-2000, which covers the dot-com bubble period, during which time analysts and investors were highly optimistic about the growth prospects of high-tech stocks. The second sub-period follows the introduction of Regulation Fair Disclosure (RegFD) and ends in 2006, a period often referred to as “the great moderation”. RegFD was promulgated by the SEC in August 2000, after which analysts lost their privileged access to corporate management. RegFD changed the information environment and to some extent the incentives analysts face (Jung et al., 2012). The final sub-period from 2007 to 2012 covers the years of the financial crisis and its aftermath. Our empirical analyses are based on the sample covering the 1995-2012 period. We repeat the empirical analysis for each of the above sub-periods, but for space reasons report without tabulating the results.

\section{Empirical results}

\subsection{Relationship between analysts' LTG forecasts and profitability mean reversion}

Panel A of Table 3 presents the results of the first-stage cross-sectional regression that is used to construct a proxy for the mean of $R O E .^{5}$ PAYOUT, $B M$ and $R \& D$ are negatively associated with ROE, while DD, LogMV and LEVERAGE are positively associated with it. Panel B reports estimates of Equation (5) that analyzes the associations between LTG

\footnotetext{
5 We use a sample pooled across firms and months for this regression test (Equation 4). As a sensitivity test, we also estimate Equation (4) for each GICS $1^{\text {st }}$ level industry, and then recalculate $E(R O E)$ and $D F E$, $N D F E, P D F E, S N D F E$, and SPDFE for each firm. We then rerun the regression tests of the study and the results are qualitatively consistent with those of our tabulated regressions.
} 
and the mean reversion variables of $R O E$. Model 1 shows that LTG is negatively associated with the deviation of $R O E$ from its mean, suggesting that analysts expect firms with higher levels of $D F E$ to have lower earnings growth rates over the next three to five years. In Model 2, the coefficient on DFE is positive, while that on $N D F E$ is negative, suggesting that, while analysts appear to consider high past $R O E$ to be associated with high medium-term earnings growth, they predict earnings of firms with below-mean past $R O E$ will grow at a faster pace in the following years. As predicted, the coefficient on SNDFE is positive and statistically significant, suggesting that analysts expect earnings growth of firms with extreme below-mean profitability to revert at a faster pace. SPDFE has the predicted negative sign, suggesting that analysts expect earnings growth of firms with extreme above-mean profitability to slow more rapidly over the next three to five years as their high profitability fades. It appears that the negative relationship between LTG and DFE in Model 1 is mainly attributable to the anticipated reversals of negative deviations and extremely negative and positive deviations of $R O E$ from its mean. The results presented in Model 3 show that LTG is negatively associated with the level of previous year $R O E$. This suggests that analysts expect firms with higher past profitability to have lower earnings growth in the next three to five years, and vice versa.

These findings suggest that analysts understand the mean reversion property of earnings, and they appear to exploit it when issuing $L T G$ forecasts. As a sensitivity check, we run the regression tests in panel B of Table 3 for the sub-periods 1995-2000, 20012006, and 2007-2012. The results (untabulated) are consistent with those reported in panel B of Table 3. The only exception is that SPDFE has the predicted sign but is not statistically significant in Model 2 for the 2007-2012 period. 
4.2.Relationships between stock recommendation and the short-term growth forecast, LTG, RLTG and RISK

The results of regression tests of our main predictions are presented in Table 4. The coefficient estimates of Equation (6a) are reported in panel A. Models 1-10 in the panel report OLS regression tests in which monthly consensus stock recommendation serves as the dependent variable. As predicted, in all the models, the coefficient on the short-term earnings growth forecast $S G$ is positive and significant at the $1 \%$ confidence level. The results for Model 2 confirm the positive relationship between stock recommendation and LTG documented in Bradshaw (2004) and Jegadeesh et al. (2004). When $L T G^{2}$ is added to the regression in Models 3-4 and 7-10, the relationship between stock recommendation and $L T G$ increases markedly and, as predicted, the $L T G^{2}$ coefficient is always negative and significant, indicating that the relationship between stock recommendation and $L T G$ is positive but diminishing.

Models 5-7 analyze the relationships between stock recommendations and the meanreversion variables (NDFE, PDFE, SNDFE and SPDFE) that are intended to serve as proxies to capture analysts' expectations about earnings growth beyond the three-to-five year $L T G$ forecast horizons, and hence also serve as a proxy for the latent variable RLTG. The coefficients on the mean-reversion variables are largely consistent with predictions, suggesting that analysts do take account of this longer-run aspect of profitability. The relationship of recommendations to the mean-reversion variables is little affected by the addition of various controls that reflect relevant aspects of uncertainty (forecast error, book-to-market, firm size) and the relationships between the risk variables and recommendations are largely consistent with predictions except for Size. In particular, Volatility is significant and negative in Models 8-10, suggesting that firms with volatile 
stock prices tend to receive less favourable stock recommendations. The coefficient on Beta is positive in all models. However, the coefficient on $L T G \times$ Beta is significant and negative in Models 9 and 10. A possible explanation for this result is that analysts tend to be cautious about firms whose future earnings have a high degree of covariance with the overall economy (Fama and French, 1995) and consequently award them with less favourable recommendations. From this we infer that Beta enters analysts’ stock rating decision-making primarily through its adverse mediating effect on the LTG sensitivity of stock recommendation.

Stock recommendations are measured on an ordinal scale. This raises the question of whether the $L T G^{2}$ variable is capturing a truncation effect caused by the upper bound on the ratings scale. To assess the sensitivity of our results to this feature, we use an Ordered Multinomial Logit regression (Model 11) to test the non-linear relationship between LTG and stock recommendations, measured as the quintile ranking of consensus stock recommendations (a 5-point scale discrete variable). Consistent with the OLS regressions, the results for Model 11 show that the likelihood of obtaining more favourable recommendations still decreases with $L T G^{2}$. This finding suggests that the OLS results cannot simply be attributed to the way recommendations have been scaled. We run all regression tests in panel A of Table 4 for the sub-periods 1995-2000, 20012006, and 2007-2012. Untabulated results reveal that these results hold for all three subperiods exception that SNDFE has the wrong sign for the period 1995-2000.

Panel B of Table 4 reports results from estimating Equation (6b), a model that allows $L T G$ to vary depending on whether the observation falls in the lowest quartile or not. Models 1-5 report the regressions based on the full 1995-2012 sample period. Contrary to prediction, the coefficient on $L T G \times L T G \_Q^{1}$, is negative in both Model 1 and Model 2, 
the latter model including the mean reversion variables, risks, and control variables. However, when allowance is made in Models 3-5 for whether the observation is in the pre- or post-financial crisis period by the inclusion of the interaction variable $L T G \times$ $L T G \_Q^{1} \times P O S T Y 06$, it is apparent that the explanation can be found in the changed economic conditions. This can be seen most clearly by comparing the results for Models 2 and 5 that include all explanatory variables in Equation (6b). The coefficient on $L T G \times$ $L T G \_Q^{1}$ in Model 5 is positive as predicted, suggesting that firm-months in the bottom quartile of $L T G$ forecasts receive more favourable stock recommendations prior to the financial crisis. However, the coefficient on $L T G \times L T G_{-} Q^{1} \times P O S T Y 06$ is negative, indicating that the predicted relationship broke down after the crisis. This finding is consistent with the interpretation that, prior to the financial crisis, analysts expect future earnings of firms in the bottom quartile of $L T G$ forecasts to grow at an increased rate over longer horizons due to the reversals in profitability, and they issue more favourable recommendations accordingly, but their beliefs that mean reversion would apply were punctured by the crisis. These results are confirmed in the separate regressions based on the sub-periods 1995-2006 and 2007-2012 (Models 6-9). The reasons are unclear, but may be due to how much analyst recommendations changed after the crisis. The relationships between recommendations and $S G$, the non-linear mean reversion variables, and the risk measures are qualitatively the same as those reported in panel A.

Our theoretical framework suggests that $L T G$ is an important determinant of stock recommendations. It may also be a function of stock recommendations. If $L T G$ and recommendations are jointly determined, OLS parameter estimates could be biased and inconsistent. To investigate the potential endogeneity between recommendations and $L T G$, and its potential influence on the coefficient estimates of our regression analyses, 
we use simultaneous equations methods to explore our main predictions. The results of a Hausman (1983) specification error test confirm that LTG and stock recommendations are endogenous. We therefore use a two-stage least squares (2SLS) regression analysis to rerun the main regression tests in Table 4. The untabulated results of the simultaneousequation specification are consistent with those reported in previous sections. Hence, we conclude that the findings and inferences reported in previous sections hold after the endogeneity bias between $R E C$ and $L T G$ is taken into account.

\subsection{Relationship between profitability of stock recommendations and analysts' consideration of really long-term growth and risk}

In this section, we empirically explore whether analysts' incorporation of $R L T G$ into their recommendation decisions positively affects the profitability of those recommendations. Risk analysis is undoubtedly an important part of securities appraisal. We also analyze how analysts' risk analysis can impact the profitability of their stock recommendations. Specifically, we seek to answer two questions: (1) Do analysts who consider the really long-term growth make more profitable stock recommendations than those who do not? (2) Do analysts who consider both really long-term growth and risk make more profitable stock recommendations? We use individual analyst recommendations and earnings forecasts along with $L T G$ for this empirical analysis.

We identify which analysts are capturing $R L T G$ when making recommendations by estimating the following reduced form of Equation (6a) by analyst for every analyst for whom we have at least 60 observations: ${ }^{6}$

\footnotetext{
${ }^{6}$ We estimate a reduced form of Equation (6) here because many of the analyst subsamples that contain the recommendation variable and proxies for $R L T G$ are rather small (mean=21.61; Q3=26). The statistical
} 


$$
R E C^{\text {individual }}=\alpha+\beta_{1} D F E+\varepsilon
$$

where $R E C^{\text {individual }}$ represents individual analyst stock recommendations, $D F E$, as discussed in section 2.2, represents the deviation of the firm's prior-year $R O E\left(R O E_{t-1}\right)$ from its expected value. We then define a variable $A N Y S T \_R L T G$, which is set equal to 1 if $\beta_{1}$ is negative, and 0 if it is positive, on the assumption that analysts with negative $\beta_{1}$ are paying attention to the mean reversion property of profitability and as such are more likely to take into account $R L T G$ than are those with positive $\beta_{1}$ estimates. ${ }^{7}$ We then identify analysts who consider both $R L T G$ and risk in making profitable recommendations by estimating the following regression:

$$
R E C^{\text {individual }}=\alpha+\beta_{1} D F E+\beta_{2} \text { Volatility }+\varepsilon
$$

where $R E C^{\text {individual }}$ and DFE are defined as earlier, and Volatility represents the twelvemonth historical stock price volatility. We classify analysts who take into account both $R L T G$ and Volatility when $\beta_{1}$ and $\beta_{2}$ estimates in their respective regressions are both negative, regardless of statistical significance; all remaining analysts are classified as those who do not take both $R L T G$ and risk into consideration. We use an indicator variable $A N Y S T \_R L T G V O L$ that is equal to 1 if $\beta_{1}$ and $\beta_{2}$ are both negative, and 0 otherwise, to capture the two groups.

We examine the returns of stock recommendations issued by the 1,262 analysts for whom we have the necessary data. We calculate accumulative abnormal returns from event date $t$ (the announcement day of the recommendation) to $t+s$. We examine three

power of regressions including all explanatory variables in Equation (6a) would not be sufficient to make reliable inferences in many analyst regressions.

7 We choose to not base the classifications on both the sign and statistical significance of $\beta_{1}$ because of the concern that we are likely to face major power problems associated with small sizes of analyst subsamples. 
return periods: a short 3-day event window (t-1 to $t+1)$, a one-month window $(t+30)$, and a twelve-month window (t+365). Following previous studies (e.g., Womack, 1996; Bradshaw, 2004), we calculate the size-adjusted abnormal return for a given firm’s recommendation by subtracting the appropriate CRSP market capitalization decile returns from the firm's raw return given on the appropriate CRSP NYSE/AMEX/NASDAQ index data file. We also calculate standard deviation-adjusted abnormal returns by subtracting the appropriate CRSP standard deviation decile portfolio returns from the raw return of the sample firm given on the CRSP NYSE/AMEX or NASDAQ index file. We follow Ertimur et al. (2007) by notionally investing \$1 in the stock for "buy" and "strong buy” recommendations, and going short \$1 for "hold,” “sell,” and "strong sell” recommendations.

We use a multivariate regression analysis to examine the relationship between abnormal returns of recommendations and indicator variables ANYST_RLTG and ANYST_RLTGVOL, which measure analyst incorporation of $R L T G$ and risk. We include the following characteristic variables at the brokerage firm, analyst, and firm level in our regressions to control for factors that could affect recommendation profitability. We include the natural logarithm of the number of analysts employed by a brokerage firm (LogBSIZE) to control for brokerage firm size because analysts at large brokerage firms have access to more resources, can benefit from their firms' stronger marketing abilities and they appear to issue more profitable stock recommendations (Clement, 1999; Stickel, 1995; Ertimur et al., 2007). As proxies for analyst time constraints, the number of firms and industries covered by an analyst are expected to negatively impact forecast accuracy and recommendation profitability (Clement, 1999; Ertimur et al., 2007). We therefore include the number of firms an analyst covers in a given year ( $\left.N \_F I R M\right)$, as well as the 
number of industries covered by the analyst in a given year ( $\left.N \_I N D\right)$. We include the number of EPS 1 forecasts issued by an analyst for a firm in a given year $\left(F R E Q^{E P S}\right)$ to proxy for analyst effort (Clement, 1999; Jung et al., 2012). We use the number of years an analyst has issued recommendations for a firm (FIRM_EXP), which is a firm-specific measure of experience, to control for analyst experience (Clement, 1999). Ertimur et al. (2007) show that earnings forecast accuracy is positively associated with recommendation profitability. We measure analyst forecast accuracy (ACCUR) as the absolute value of the difference between the actual earnings of a given fiscal year and the analyst's last EPS ${ }_{1}$ forecast for that year, deflated by the absolute value of actual earnings. Firms with a high level of analyst following have better information environments and therefore stock reactions to recommendations of these firms are expected to be relatively weaker (e.g., Stickel, 1995). We use the number of analysts following a firm in a given year ( $\left.N \_A N Y S T\right)$ to capture this effect. We include the natural logarithm of the market value of the last fiscal year ( $\log M V)$ because market reactions to stock recommendations of small firms with poorer information environments tend to be stronger (e.g., Stickel, 1995). We include in the regression model the book-to-market ratio of the last fiscal year $(B M)$ and an indicator variable of loss-making (LOSS) that is equal to 1 if the earnings before extraordinary items of the firm in a given year is negative, and 0 otherwise.

We estimate Equation (9a) to examine whether analysts who consider $R L T G$ make more profitable stock recommendations:

$$
\begin{aligned}
C A R_{(t, t+s)}= & \alpha+\beta_{1} \text { ANYST } \_ \text {RLTG }+\beta_{2} \text { LogBSize }+\beta_{3} N_{-} \text {FIRM }+\beta_{4} N_{-} \text {IND } \\
& +\beta_{5} F R E Q^{E P S}+\beta_{6} A C C U R+\beta_{7} \text { FIRM }{ }_{-} E X P+\beta_{8} N_{-} \text {ANYST }+\beta_{9} L O S S \\
& +\beta_{10} B M+\beta_{11} \text { LogMV }+ \text { Industry effects }+ \text { Year effects }+\varepsilon
\end{aligned}
$$


where $C A R_{(t, t+s)}$ represents the cumulative (size- or standard deviation-adjusted) abnormal return to the stock from recommendation announcement day $t$ to $t+s$. The ANYST_RLTG indicator variable measures analyst incorporation of $R L T G$. We consider a positive and statistically significant estimate of $\beta_{1}$ as evidence that analysts who take into account $R L T G$ make more profitable stock recommendations. We also control for year and industry effects. We cluster standard errors by analyst to correct for serial correlation.

We estimate Equation (9b) to examine whether analysts who capture both $R L T G$ and risk make more profitable stock recommendations:

$$
\begin{aligned}
& \mathrm{CAR}_{(t, t+s)}=\alpha+\beta_{1} \text { ANYST_RLTGVOL }+\beta_{2} \text { LogBSize }+\beta_{3} N_{-} \text {FIRM }+\beta_{4} N_{-} \text {IND } \\
& +\beta_{5} \text { FREQ }{ }^{E P S}+\beta_{6} \text { ACCUR }+\beta_{7} F I R M_{-} E X P+\beta_{8} N_{-} \text {ANYST }+\beta_{9} L O S S \\
& +\beta_{10} B M+\beta_{11} \log M V+\text { Industry effects }+ \text { Year effects }+\varepsilon
\end{aligned}
$$

The ANYST_RLTGVOL indicator variable measures analyst incorporation of both $R L T G$ and risk. We consider a positive and significant estimate of $\beta_{1}$ as evidence that analysts who take account of both $R L T G$ and risk make more profitable stock recommendations.

We collect individual analyst stock recommendations, as well as $E P S_{1}$, and $L T G$ forecasts from I/B/E/S for the 1995-2012 sample period. Accounting data come from COMPUSTAT, and stock return data come from CRSP. Among the 1,262 analysts in our sample, we find that 782 consider or are likely to consider $R L T G$ when making recommendations (ANYST_RLTG=1), and the remaining 480 do not or are not likely to incorporate $R L T G$ or earnings changes over time (ANYST_RLTG $=0$ ). The two groups issued a total of 240,366 stock recommendations during the sample period.

We perform univariate tests of mean and median differences of abnormal returns and the control variables between the two analyst groups and the untabulated findings are as follows. The recommendations issued by the $A N Y S T \_R L T G=1$ group analysts tend to be 
more favourable. The means of the size-adjusted abnormal returns on the recommendations issued by analysts who tend to consider $R L T G$ are statistically significantly higher than those of the recommendations issued by analysts who do not take account of RLTG. Furthermore, for all three return periods, the means and the medians of the standard deviation-adjusted returns of the ANYST_RLTG=1 group are both statistically higher than those of the $A N Y S T \_R L T G=0$ group. Analysts who tend to take account of $R L T G$ are generally employed by larger brokerage firms, and they appear to follow fewer industries and have more firm-specific experience than those who do not capture RLTG. They also appear to issue earnings forecasts more frequently and with lower forecast errors than those who do not incorporate RLTG. Finally, analysts who tend to take $R L T G$ into account generally cover smaller firms with relatively lower analyst followings.

The results for Equation (9a) are reported in panel A of Table 5. The $\mathrm{R}^{2} \mathrm{~s}$ of the regressions are low, indicating (unsurprisingly) that stock returns are affected by many sources of news in addition to analysts' forecasts. The resultant coefficient estimates are unbiased but therefore lack precision. With that caveat in mind, the results reveal that the ANYST_RLTG coefficient is statistically significant at least at the $10 \%$ confidence level for all return periods, suggesting that analysts who consider earnings growth beyond the next three to five years are able to provide more profitable stock recommendations to investors. The direction of the effect of the control variables are broadly as expected. The results for Equation (9b) are reported in panel B of Table 5. Overall, the results for ANYST_RLTGVOL are weaker than for ANYST_RLTG, but they tend to suggest that analysts who take account of both $R L T G$ and risk generate higher abnormal returns. The results of control variables are similar to those in panel A of Table 5. 
Our analysis uses DFE to proxy for $R L T G$. As a test of the reliability of this measure, we calculate the realized actual earnings growth rate over the next year, five years, and six to ten years ${ }^{8}$ in order to shed light on the extent to which DFE predicts actual earnings growth rates in the future. Untabulated results reveal that $D F E$ is negatively associated with the realized actual earnings growth rates in the subsequent ten years. We interpret this as suggesting that above (below) mean profitability is associated with declines (rises) in the realized actual earnings growth rates, which suggests that $D F E$ is indeed a reasonable proxy for very long run profitability. In addition, we perform regressions to examine the relationship between firms' raw returns and DFE. The untabulated results show that DFE is negatively associated with both one- and twelve-month returns, thereby suggesting that the stock market prices the change in the earnings growth rate over time correctly and in a way that is consistent with how it is related to analyst recommendations.

\section{Summary and concluding remarks}

Our study aims to enhance the understanding of analysts’ stock recommendation decisions. We present a valuation framework that provides a way of thinking about the linkages between analyst recommendations and their expectations about earnings growth over the short-term, medium-term, and the really long-term future. We present results suggesting that while positive, the effect of $L T G$ on stock recommendations declines the greater is $L T G$, which we attribute to the attenuating effect of earnings growth beyond the LTG forecast horizons ( $R L T G$ ) on the analysts' value estimates for the stock, and hence

\footnotetext{
${ }^{8}$ We calculate the actual five-year average earnings growth rate by fitting a least squares growth line to the logarithms of six earnings before extraordinary items, a method used by I/B/E/S.
} 
on their stock recommendations. For the first time in the literature, we employ profitability mean reversion variables from prior empirical literature to proxy for analysts' unobservable expectations about earnings growth beyond the LTG forecast horizons. We show how RLTG is associated with analysts' stock recommendations and that the effort analysts exert to study earnings growth beyond the $L T G$ forecast horizons and risk enhances recommendation profitability.

To summarize, our study provides insights into analysts’ stock recommendation decisions. Our findings suggest that it is important for empirical studies to explicitly recognize the really long-term growth factor when examining the relationship between stock returns and firms’ future earnings and growth. Our proxy for the really long-term growth predicts the realized actual earnings growth rates over the next ten years, and thus could potentially act as a proxy for this latent variable. Furthermore, our study provides additional evidence that analysts’ fundamental analyses, such as investigations into firms’ growth prospects and risk, promotes the efficient allocation of financial resources in the capital market. 


\section{References}

Barker, R. G., 1999, The role of dividends in valuation models used by analysts and fund managers, European Accounting Review 8, 195-218.

Barniv, R., O-K. Hope, M. Myring, and W. B. Thomas, 2009, Do analysts practice what they preach and should investors listen? Effects of recent regulations, Accounting Review 84, 1015-1039.

Block, S. B., 1999, A study of financial analysts: Practice and theory, Financial Analysts Journal 55, 86-95.

Boni, L. and K. L. Womack, 2006, Analysts, industries, and price momentum, Journal of Financial and Quantitative Analysis 41, 85-109.

Bradshaw, M. and R. Sloan, 2002, GAAP versus the street: An empirical assessment of two alternative definitions of earnings, Journal of Accounting Research 40, 41-66.

Bradshaw, M. T., 2002, The use of target price to justify sell-side analysts’ stock recommendations, Accounting Horizon 16, 27-41.

Bradshaw, M. T., 2004, How do analysts use their earnings forecasts in generating stock recommendations? Accounting Review 79, 25-50.

Bradshaw, M.T., 2011, Analysts' Forecasts: What do we know after decades of work? Working paper (Boston College).

Brooks, L.D., and Buckmaster, D.A., 1976, Further evidence of the time series properties of accounting income, Journal of Finance 31, 1359-1373.

Brown, L., 1993, Earnings Forecasting Research: Its implications for capital markets research, International Journal of Forecasting 9, 295-320.

Brown, L., ed. 2000, I/B/E/S Research Bibliography: Sixth Edition. I/B/E/S International Inc., New York, NY.

Brown, L., A.C. Call, M.B. Clement, and N. Y. Sharp, 2015, Inside the "Black Box" of sell-side financial analysts, Journal of Accounting Research 53, 1-47.

Choi, Y.M. , H.K. Ju, and Y. K. Park, 2011, Do dividend changes predict the future profitability of firms? Accounting \& Finance 51, 869-891.

Clement, M., 1999, Analyst forecast accuracy: Do ability, resources, and portfolio complexity matter? Journal of Accounting and Economics 27, 285-303.

Dechow, P. M. and R. G. Sloan, 1997, Returns to constrain investment: Tests of the naïve expectations hypotheses, Journal of Financial Economics 43, 3-28. 
Ertimur, Y., Sunder, J., and Sunder, S.V., 2007, Measure for measure: The relation between forecast accuracy and recommendation profitability of analysts, Journal of Accounting Research 45, 567-606.

Fairfield, P., Ramnath, S., and Yohn, T., 2009, Do industry-level analyses improve forecasts of financial performance? Journal of Accounting Research 47, 147-178.

Fama, E. F. and K. R. French, 1992, The cross-section of expected stock returns, Journal of Finance 47, 427-465.

Fama, E. F. and K. R. French, 1995, Size and book-to-market factors in earnings and returns, Journal of Finance 50, 131-156.

Fama, E. F. and K. R. French, 1999, The corporate cost of capital and the return on corporate investment, Journal of Finance 54, 1939-1967.

Fama, E. F. and K. R. French, 2000, Forecasting profitability and earnings, Journal of Business 73, 161-175.

Francis, J. and D. Philbrick, 1993, Analysts' decisions as products of multi-task environment, Journal of Accounting Research 31, 216-230.

Freeman, R. N., Ohlson, J.A., and S.H. Penman, 1982, Book rate-of-return and prediction of earnings changes: An empirical investigation, Journal of Accounting Research 20, 639-653.

He, P.W, A. Grant, and J. Fabre, 2013, economic value of analyst recommendations in Australia: An application of the Black-Litterman asset allocation model, Accounting \& Finance 53, 441-470.

Jackson, A. R., 2005, Trading generation, reputation, and sell-side analysts, Journal of Finance 60, 671-717.

Jegadeesh, N., J. Kim, S.D. Krische, and C. Lee, 2004, Analyzing the analysts: When do recommendations add value? Journal of Finance 59, 1083-1124.

Jung, B., P. Shane, and Y.S. Yang, 2012, Do financial analysts' long-term growth forecasts matter? Evidence from stock recommendations and career outcomes, Journal of Accounting and Economics 53, 55-76.

Kecskes, A., R. Michaely, and K. Womack, 2009, What drives the value of analysts' recommendations: Earnings estimates or discount rate estimates? Working paper, (University of Toronto)

La Porta, R., 1996, Expectations and the cross-section of stock returns, Journal of Finance 51, 1715-1742. 
Lin, H. and M. F. McNichols, 1998, Underwriting relationships, analysts' earnings forecasts and investment recommendations, Journal of Accounting and Economics 25, 101-127.

Lintner, J., 1965, The valuation of risk assets and the selection of risky investments in stock portfolios and capital budgets, Review of Economics and Statistics 47, 13-37.

Malkiel, B. and Y. Xu, 1997, Risk and return revisited, Journal of Portfolio Management 23, 9-14.

Malkiel, B. and Y. Xu, 2006, Idiosyncratic risk and securities returns, Working paper (University of Texas at Dallas).

Merton, R.C., 1987, A simple model of capital market equilibrium with incomplete information, Journal of Finance 42, 483-510.

Miller, M.H. and F. Modigliani, 1961, Dividend policy, growth, and the valuation of shares, Journal of Business 34, 411-433.

Ohlson, J. A. and B. Juettner-Nauroth, 2005, Expected EPS and EPS growth as determinants of value, Review of Accounting Studies 10, 349-365.

Petersen, M. A., 2009, Estimating standard errors in finance and panel data sets: comparing approaches, Review of Financial Studies 22, 435-480.

Ramnath, S., S. Rock, and P. Shane, 2008a, The financial analyst forecasting literature: A taxonomy with suggestions for further research, International Journal of Forecasting 24, 34-75.

Ramnath, S., S. Rock, and P. Shane, 2008b, Financial analysts’ forecasts and stock recommendations: A review of the research, Foundations and Trends in Finance 2, 311420.

Schipper, K., 1991, Commentary on analysts’ forecasts, Accounting Horizons 5, 105-121.

Sharpe, W., 1964, Capital asset prices: A theory of market equilibrium under conditions of risk, Journal of Finance 19, 425-442.

Stickel, S. E., 1995, The anatomy of the performance of buy and sell recommendations, Financial Analysts Journal 51, 25-39.

Stigler, G.J., 1963, Capital and rates of return in manufacturing industries (Princeton: Princeton University Press).

Womack, K. L., 1996, Do brokerage analysts' recommendations have investment value? Journal of Finance 51, 137-167. 


\section{Table 1}

\section{Data selection}

Sample period: January 1995-December 2012

Procedures

Step1: Collect consensus monthly forecasts from I/B/E/S

Stock recommendations

\begin{tabular}{rrrr} 
& & \multicolumn{2}{c}{ Remaining } \\
Obs. & Firms & Obs. & Firms \\
$1,073,545$ & 17,987 & & \\
$1,028,291$ & 17,733 & & \\
754,144 & 13,325 & &
\end{tabular}

Long-term growth forecasts (LTG)

Merge recommendations, LTG, and $\mathrm{EPS}_{1}$; eliminate duplicate monthly data points

Step2: Collect accounting data from Compustat Estimate book-to-market, LogMV, the dividiend indicator variable, payout ratio, leverage, and $\mathrm{R} \& \mathrm{D}$ ratio

Merge Compustat and I/B/E/S data

No. of firm-month observations with explanatory variables for estimating equation (4)

Step 3: Calculate ROE, SG, earnings forecast error, and other variables

Collect the last reported EPS (EPS $)_{0}$ from I/B/E/S for firm-year units with $\mathrm{I} / \mathrm{B} / \mathrm{E} / \mathrm{S}$ data

$68,677 \quad 12,240$

$530,952 \quad 8,480$

Calculate ROE for observations with positive book value

Remaining observations for estimating equations (4) and (5)

Calculate SG for firm-month units with positive $\mathrm{EPS}_{0}$

Step 4: Estimate risk variables using CRSP data

Calculate the five-year market beta for firm-month units

Calculate the annualized 3-month stock price volatility

Calculate idiosyncratic risk and the systematic risk component using one year daily return data

Merge CRSP, Compustat, and I/B/E/S data

Eliminate the $1 \%$ of the lowest and highest tails of all variables

except for $R E C$.

Remaining observations with all data items for estimating equation (6a)

$284,655 \quad 4,946$

This table describes our sample selection. The first two numeric columns report the number of firm-month (firm-year, in the case of accounting data) observations and firms. The next two columns report the number of firm-month observations and firms remained after each of the data merging and elimination procedures. At the first step, monthly consensus stock recommendations, long-term growth forecasts, and EPS ${ }_{1}$ are collected from I/B/E/S. The three data items are merged based on the estimation dates of I/B/E/S consensus forecasts (the third Thursday). At the second step, accounting data are collected from COMPUSTAT to estimate the variables in equation (4). Accounting data are merged with I/B/E/S forecasts. At step 3, $R O E$ and $S G$ are estimated using the last reported earnings per share $\left(\mathrm{EPS}_{0}\right)$ collected from the detailed actuals file of the I/B/E/S. At step 4, for each observation with I/B/E/S analyst data, the five-year market beta and the annualized three-month stock price volatility are estimated using the CRSP return data. The one-year stock price volatility, its systematic risk component, and idiosyncratic risk are estimated using daily return data twelve months preceding the estimation dates of consensus recommendations. CRSP data are merged with I/B/E/S and COMPUSTAT data. To mitigate the potential influence of outliers, we trim the $1 \%$ of the lowest and highest tails of all variables except for stock recommendations. 
Table 2

Descriptive statistics and correlation analysis

$\begin{array}{lcrrrrrrr}\text { Panel A: Descriptive Statistics } & & & & & & \\ \text { Variable } & \text { Mean } & \text { Std Dev } & \underline{\text { Min }} & \underline{\text { Q1 }} & \underline{\text { Median }} & \underline{\text { Q3 }} & \underline{\text { Max }} & \text { N } \\ \text { REC } & 3.782 & 0.617 & 1.000 & 3.350 & 3.800 & 4.200 & 5.000 & 744,323 \\ \text { LTG } & 0.170 & 0.098 & 0.010 & 0.100 & 0.150 & 0.200 & 0.600 & 730,230 \\ \text { SG } & 0.192 & 0.703 & -2.713 & -0.021 & 0.129 & 0.295 & 6.136 & 582,168 \\ \text { ROE } & 0.086 & 0.155 & -1.222 & 0.045 & 0.093 & 0.147 & 0.681 & 520,543 \\ \text { DFE } & -0.002 & 0.070 & -0.134 & -0.049 & -0.010 & 0.032 & 0.300 & 405,172 \\ \text { NDFE } & -0.027 & 0.034 & -0.134 & -0.049 & -0.010 & 0.000 & 0.000 & 409,313 \\ \text { PDFE } & 0.025 & 0.047 & 0.000 & 0.000 & 0.000 & 0.032 & 0.300 & 409,299 \\ \text { Beta } & 1.085 & 0.677 & -0.127 & 0.592 & 0.973 & 1.454 & 3.537 & 435,305 \\ \text { Volatility } & 0.476 & 0.263 & 0.128 & 0.286 & 0.409 & 0.594 & 1.620 & 595,425 \\ \text { LogMV } & 6.741 & 1.720 & 3.074 & 5.475 & 6.605 & 7.865 & 11.379 & 551,248 \\ \text { BM } & 0.535 & 0.355 & 0.044 & 0.283 & 0.460 & 0.693 & 2.374 & 538,406 \\ \text { R\&D } & 0.042 & 0.090 & 0.000 & 0.000 & 0.000 & 0.040 & 0.794 & 567,196 \\ \text { LEVERAGE } & 0.538 & 0.245 & 0.066 & 0.344 & 0.540 & 0.717 & 1.189 & 563,717 \\ \text { DD } & 0.462 & 0.499 & 0.000 & 0.000 & 0.000 & 1.000 & 1.000 & 573,631 \\ \text { PAYOUT } & 0.240 & 0.422 & 0.000 & 0.000 & 0.047 & 0.339 & 4.013 & 463,221 \\ \text { Forecast Error } & 0.227 & 0.820 & -1.167 & -0.057 & 0.000 & 0.167 & 8.000 & 687,327\end{array}$


Table 2 (continued)

Panel B: Pearson Correlation (significance levels are in parentheses)

\begin{tabular}{|c|c|c|c|c|c|c|c|c|c|c|c|c|c|}
\hline & REC & LTG & SG & ROE & DFE & Beta & Volatility & LogMV & $\mathrm{BM}$ & $R \& D$ & LEVERAGE & DD & PAYOUT \\
\hline \multirow[t]{2}{*}{ REC } & - & 0.296 & 0.155 & 0.030 & -0.038 & 0.069 & 0.051 & -0.091 & -0.174 & 0.032 & -0.120 & -0.167 & -0.178 \\
\hline & & $(0.001)$ & $(0.001)$ & $(0.001)$ & $(0.001)$ & $(0.001)$ & $(0.001)$ & $(0.001)$ & $(0.001)$ & $(0.001)$ & $(0.001)$ & $(0.001)$ & $(0.001)$ \\
\hline \multirow[t]{2}{*}{ LTG } & & - & 0.158 & -0.221 & -0.111 & 0.303 & 0.416 & -0.221 & -0.269 & 0.369 & -0.384 & -0.449 & -0.306 \\
\hline & & & $(0.001)$ & $(0.001)$ & $(0.001)$ & $(0.001)$ & $(0.001)$ & $(0.001)$ & $(0.001)$ & $(0.001)$ & $(0.001)$ & $(0.001)$ & $(0.001)$ \\
\hline \multirow[t]{2}{*}{ SG } & & & & -0.193 & -0.243 & 0.039 & -0.022 & -0.027 & -0.066 & 0.038 & -0.025 & -0.066 & 0.021 \\
\hline & & & & $(0.001)$ & $(0.001)$ & $(0.001)$ & $(0.001)$ & $(0.001)$ & $(0.001)$ & $(0.001)$ & $(0.001)$ & $(0.001)$ & $(0.001)$ \\
\hline \multirow[t]{2}{*}{ ROE } & & & & - & 0.878 & -0.151 & -0.253 & 0.265 & -0.205 & -0.253 & 0.110 & 0.207 & 0.004 \\
\hline & & & & & $(0.001)$ & $(0.001)$ & $(0.001)$ & $(0.001)$ & $(0.001)$ & $(0.001)$ & $(0.001)$ & $(0.001)$ & $(0.007)$ \\
\hline \multirow[t]{2}{*}{ DFE } & & & & & - & 0.037 & 0.060 & -0.012 & 0.036 & 0.017 & -0.028 & -0.010 & -0.013 \\
\hline & & & & & & $(0.001)$ & $(0.001)$ & $(0.001)$ & $(0.001)$ & $(0.001)$ & $(0.001)$ & $(0.001)$ & $(0.001)$ \\
\hline \multirow[t]{2}{*}{ Beta } & & & & & & - & 0.332 & -0.036 & -0.009 & 0.311 & -0.228 & -0.347 & -0.233 \\
\hline & & & & & & & $(0.001)$ & $(0.001)$ & $(0.001)$ & $(0.001)$ & $(0.001)$ & $(0.001)$ & $(0.001)$ \\
\hline \multirow{2}{*}{ Volatility } & & & & & & & - & -0.323 & 0.029 & 0.272 & -0.218 & -0.38 & -0.201 \\
\hline & & & & & & & & $(0.001)$ & $(0.001)$ & $(0.001)$ & $(0.001)$ & $(0.001)$ & $(0.001)$ \\
\hline \multirow[t]{2}{*}{ LogMV } & & & & & & & & - & -0.277 & -0.081 & 0.159 & 0.373 & 0.170 \\
\hline & & & & & & & & & $(0.001)$ & $(0.001)$ & $(0.001)$ & $(0.001)$ & $(0.001)$ \\
\hline \multirow[t]{2}{*}{$\mathrm{BM}$} & & & & & & & & & & -0.171 & 0.134 & 0.041 & 0.057 \\
\hline & & & & & & & & & & $(0.001)$ & $(0.001)$ & $(0.001)$ & $(0.001)$ \\
\hline \multirow[t]{2}{*}{$R \& D$} & & & & & & & & & & & -0.36 & -0.304 & -0.163 \\
\hline & & & & & & & & & & & $(0.001)$ & $(0.001)$ & $(0.001)$ \\
\hline \multirow[t]{2}{*}{ LEVERAGE } & & & & & & & & & & & - & 0.344 & 0.218 \\
\hline & & & & & & & & & & & & $(0.001)$ & $(0.001)$ \\
\hline \multirow[t]{2}{*}{ DD } & & & & & & & & & & & & - & 0.545 \\
\hline & & & & & & & & & & & & & $(0.001)$ \\
\hline AYOU & & & & & & & & & & & & & \\
\hline
\end{tabular}


Panel A of the table describes the main variables used in empirical analysis. Panel B of the table presents Pearson correlation analysis of the main variables used in empirical analysis.

Variable Definitions:

\author{
REC = monthly analysts' consensus (mean) stock recommendation from the I/B/E/S database; \\ $L T G=$ monthly analysts' consensus (median) long-term growth forecast from I/B/E/S; \\ SG = analyst forecast of short-term earnings growth rate, measured as the difference between \\ analyst consensus one-year-ahead earnings per share forecast and the last reported \\ earnings per share (both from $\mathrm{I} / \mathrm{B} / \mathrm{E} / \mathrm{S}$ ) divided by the last reported earnings per share, \\ i.e., $\left(\mathrm{EPS}_{1}-\mathrm{EPS}_{0}\right) / \mathrm{EPS}_{0}$, when $\mathrm{EPS}_{0}>0$; \\ $R O E$ = return on equity as of the prior fiscal year, measured as the last reported earnings per \\ share before extraordinary items divided by book value per share; \\ $D F E$ = deviation of return on equity from its mean, measured as the difference between return \\ on equity as of the prior fiscal year (ROE) and its expected value, E(ROE), the fitted \\ value from a cross-sectional regression; \\ $N D F E$ = negative deviations of ROE from its mean, equal to DFE when DFE is negative and 0 \\ otherwise; \\ $P D F E=$ positive deviations of ROE from its mean, equal to DFE when DFE is positive and 0 \\ otherwise; \\ Beta = five-year market beta, estimated using CRSP monthly firm and market returns over a 5- \\ year period based on the CAPM, i.e. ret $_{i}=\alpha+\beta M K T r e t+\varepsilon$; \\ Volatility $=$ three-month stock price volatility, estimated as annualized three-month standard \\ deviation of daily stock returns from CRSP; \\ $B M=$ book-to-market ratio as of the prior fiscal year, measured as book value divided by \\ market value; \\ $\log M V=$ natural logarithm of market value, which is estimated as the number of shares \\ outstanding multiplied by stock price at the end of the fiscal year; \\ $D D=$ indicator variable taking the value of 1 if the firm issues common dividends in year $t$, and \\ 0 otherwise; \\ PAYOUT $=$ dividend payout ratio, measured as total common dividends divided by earnings before \\ extraordinary items if earnings before extraordinary items $>0$ or measured as total \\ common dividends divided by $(0.08 *$ common equity) if earnings before extraordinary \\ items $<0$; \\ $R \& D=$ research and development expense divided by net sales; \\ LEVERAGE = total liabilities divided by total assets; and \\ Forecast Error = signed analyst EPS ${ }_{1}$ forecast error, measured as the difference between $\mathrm{EPS}_{1}$ and the \\ actual earnings per share $\left(E^{2} S_{a}\right)$ scaled by the absolute value of $E P S_{a}$.
}


Table 3

Relationship between analyst long-term growth forecast and profitability

Panel A: Regression to explain the level of ROE

$$
R O E=d_{0}+d_{1} B M+d_{2} D D+d_{3} P A Y O U T+d_{4} L O g M V+d_{5} R D+d_{6} L E V E R A G E+\varepsilon
$$

$\begin{array}{lcc}\text { Model } & \text { Predicted sign } & \underline{1} \\ \text { Intercept } & ? & 0.122 \\ & & (0.001) \\ \text { BM } & - & -0.106 \\ & & (0.001) \\ \text { DD } & + & 0.002 \\ & & (0.001) \\ \text { PAYOUT } & - & -0.009 \\ & & (0.001) \\ \text { LogMV } & + & 0.005 \\ & & (0.001) \\ \text { R\&D } & +/- & -0.063 \\ & & (0.001) \\ \text { LEVERAGE } & + & 0.052 \\ & & (0.001) \\ \text { n } & & 401,451 \\ \text { Adj } R^{2} & & 0.172\end{array}$

Panel B: Relationship between LTG and profitability mean reversion variables

$$
L T G=\alpha+b_{1} D F E+b_{2} N D F E+b_{3} S N D F E+b_{4} S P D F E+\varepsilon
$$

$\begin{array}{lcrrr}\text { Model } & \text { Predicted sign } & \underline{1} & \underline{2} & \underline{3} \\ \text { Intercept } & ? & 0.155 & 0.144 & 0.176 \\ & & (0.001) & (0.001) & (0.001) \\ \text { DFE } & - & -0.128 & 0.065 & \\ & - & (0.001) & (0.001) & \\ \text { NDFE } & & & -0.228 & \\ & + & & (0.001) & \\ \text { SNDFE } & - & & 2.720 & \\ & & & (0.001) & \\ \text { SPDFE } & - & -0.147 & \\ & & & (0.001) & \\ \text { ROE } & & & & -0.132 \\ & & & & (0.001) \\ \mathrm{n} & & 401,451 & 401,451 & 512,837 \\ \text { Adj } R^{2} & & 0.012 & 0.030 & 0.049\end{array}$

Panel A of the table reports the coefficient estimates and $p$-values (in parentheses) of the regression explaining the level of return on equity. Panel B of the table reports the results of regression tests that 
analyze the associations between $L T G$ and measures of the mean reversion of profitability. The dependent variable, $L T G$, represents monthly (median) long-term growth forecasts. We adjust the standard errors of the regression slopes in the regression tests for the possible dependence in residuals by clustering standard errors on firm and month dimensions. SNDFE, the square of DFE when DFE is negative and 0 otherwise; $S P D F E$, the square of DFE when DFE is positive and 0 otherwise. See also Table 2 for variable definitions. 
Table 4

Relationships between stock recommendations and analysts' earnings growth forecasts and risk measures

\begin{tabular}{|c|c|c|c|c|c|c|c|c|c|c|c|c|c|}
\hline \multicolumn{14}{|c|}{$\begin{array}{c}R E C=\alpha_{0}+\beta_{1} S G+\beta_{2} L T G+\beta_{3} L T G^{2}+\beta_{4} N D F E+\beta_{5} P D F E+\beta_{6} S N D F E+\beta_{7} S P D F E+\beta_{8} \text { Forecast Error }+\gamma_{1} \text { Beta }+\gamma_{2} L T G \times \text { Beta } \\
+\gamma_{3} \text { Volatility }+\gamma_{4} L T G \times \text { Volatility }+\gamma_{5} L o g M V+\gamma_{6} B M+\sum^{9} \delta_{j} \text { Industry Dummy }+\sum^{2012} \theta_{i} \text { Yr Dummy }+\varepsilon\end{array}$} \\
\hline \multicolumn{2}{|c|}{ Dependent variable } & \multicolumn{10}{|c|}{$\begin{array}{c}\text { OLS Estimates } \\
\text { (consensus stock recommendation) }\end{array}$} & \multicolumn{2}{|c|}{$\begin{array}{c}\text { Ordered Multinomial Logit } \\
\text { Regression Estimates } \\
\text { (LTG quintile ranking) }\end{array}$} \\
\hline Model & & $\underline{1}$ & $\underline{2}$ & $\underline{3}$ & $\underline{4}$ & $\underline{5}$ & $\underline{6}$ & $\underline{7}$ & $\underline{8}$ & $\underline{9}$ & $\underline{10}$ & & \\
\hline & Pred. sign & & & & & & & & & & & Estimate & Odds Ratio \\
\hline Intercept & + & $\begin{array}{c}3.756 \\
(0.001)\end{array}$ & $\begin{array}{c}3.469 \\
(0.001)\end{array}$ & $\begin{array}{c}3.207 \\
(0.001)\end{array}$ & $\begin{array}{c}3.177 \\
(0.001)\end{array}$ & $\begin{array}{c}3.732 \\
(0.001)\end{array}$ & $\begin{array}{c}3.721 \\
(0.001)\end{array}$ & $\begin{array}{c}3.141 \\
(0.001)\end{array}$ & $\begin{array}{c}3.113 \\
(0.001)\end{array}$ & $\begin{array}{c}3.373 \\
(0.001)\end{array}$ & $\begin{array}{c}3.320 \\
(0.001)\end{array}$ & & \\
\hline SG & + & $\begin{array}{c}0.131 \\
(0.001)\end{array}$ & & & $\begin{array}{c}0.091 \\
(0.001)\end{array}$ & & $\begin{array}{c}0.153 \\
(0.001)\end{array}$ & $\begin{array}{c}0.117 \\
(0.001)\end{array}$ & $\begin{array}{c}0.105 \\
(0.001)\end{array}$ & $\begin{array}{c}0.101 \\
(0.001)\end{array}$ & $\begin{array}{c}0.103 \\
(0.001)\end{array}$ & $\begin{array}{c}0.379 \\
(0.001)\end{array}$ & 1.461 \\
\hline LTG & + & & $\begin{array}{c}1.848 \\
(0.001)\end{array}$ & $\begin{array}{c}4.766 \\
(0.001)\end{array}$ & $\begin{array}{c}5.158 \\
(0.001)\end{array}$ & & & $\begin{array}{c}5.571 \\
(0.001)\end{array}$ & $\begin{array}{c}5.730 \\
(0.001)\end{array}$ & $\begin{array}{c}5.413 \\
(0.001)\end{array}$ & $\begin{array}{c}5.638 \\
(0.001)\end{array}$ & $\begin{array}{c}2.003 \\
(0.001)\end{array}$ & 7.411 \\
\hline $\mathrm{LTG}^{2}$ & - & & & $\begin{array}{l}-6.073 \\
(0.001)\end{array}$ & $\begin{array}{l}-6.934 \\
(0.001)\end{array}$ & & & $\begin{array}{l}-7.816 \\
(0.001)\end{array}$ & $\begin{array}{l}-8.241 \\
(0.001)\end{array}$ & $\begin{array}{l}-7.147 \\
(0.001)\end{array}$ & $\begin{array}{l}-7.139 \\
(0.001)\end{array}$ & $\begin{array}{l}-0.521 \\
(0.001)\end{array}$ & 0.594 \\
\hline NDFE & + & & & & & $\begin{array}{l}-0.109 \\
(0.248)\end{array}$ & $\begin{array}{c}0.439 \\
(0.001)\end{array}$ & $\begin{array}{c}0.634 \\
(0.001)\end{array}$ & $\begin{array}{c}0.471 \\
(0.001)\end{array}$ & $\begin{array}{c}0.560 \\
(0.001)\end{array}$ & $\begin{array}{l}0.252 \\
(0.01)\end{array}$ & $\begin{array}{c}1.238 \\
(0.001)\end{array}$ & 3.449 \\
\hline PDFE & + & & & & & $\begin{array}{c}1.061 \\
(0.001)\end{array}$ & $\begin{array}{c}1.293 \\
(0.001)\end{array}$ & $\begin{array}{c}1.055 \\
(0.001)\end{array}$ & $\begin{array}{c}0.977 \\
(0.001)\end{array}$ & $\begin{array}{c}1.008 \\
(0.001)\end{array}$ & $\begin{array}{c}0.656 \\
(0.001)\end{array}$ & $\begin{array}{c}3.999 \\
(0.001)\end{array}$ & 54.544 \\
\hline SNDFE & + & & & & & $\begin{array}{l}15.584 \\
(0.001)\end{array}$ & $\begin{array}{l}14.564 \\
(0.001)\end{array}$ & $\begin{array}{c}7.941 \\
(0.001)\end{array}$ & $\begin{array}{c}7.186 \\
(0.001)\end{array}$ & $\begin{array}{c}8.257 \\
(0.001)\end{array}$ & $\begin{array}{c}1.970 \\
(0.035)\end{array}$ & $\begin{array}{l}31.918 \\
(0.001)\end{array}$ & 7.E+13 \\
\hline SPDFE & - & & & & & $\begin{array}{l}-4.129 \\
(0.001)\end{array}$ & $\begin{array}{l}-4.929 \\
(0.001)\end{array}$ & $\begin{array}{l}-4.034 \\
(0.001)\end{array}$ & $\begin{array}{l}-4.217 \\
(0.001)\end{array}$ & $\begin{array}{l}-4.661 \\
(0.001)\end{array}$ & $\begin{array}{l}-3.376 \\
(0.001)\end{array}$ & $\begin{array}{r}-18.555 \\
(0.001)\end{array}$ & 0.000 \\
\hline
\end{tabular}


Panel A: (continued)

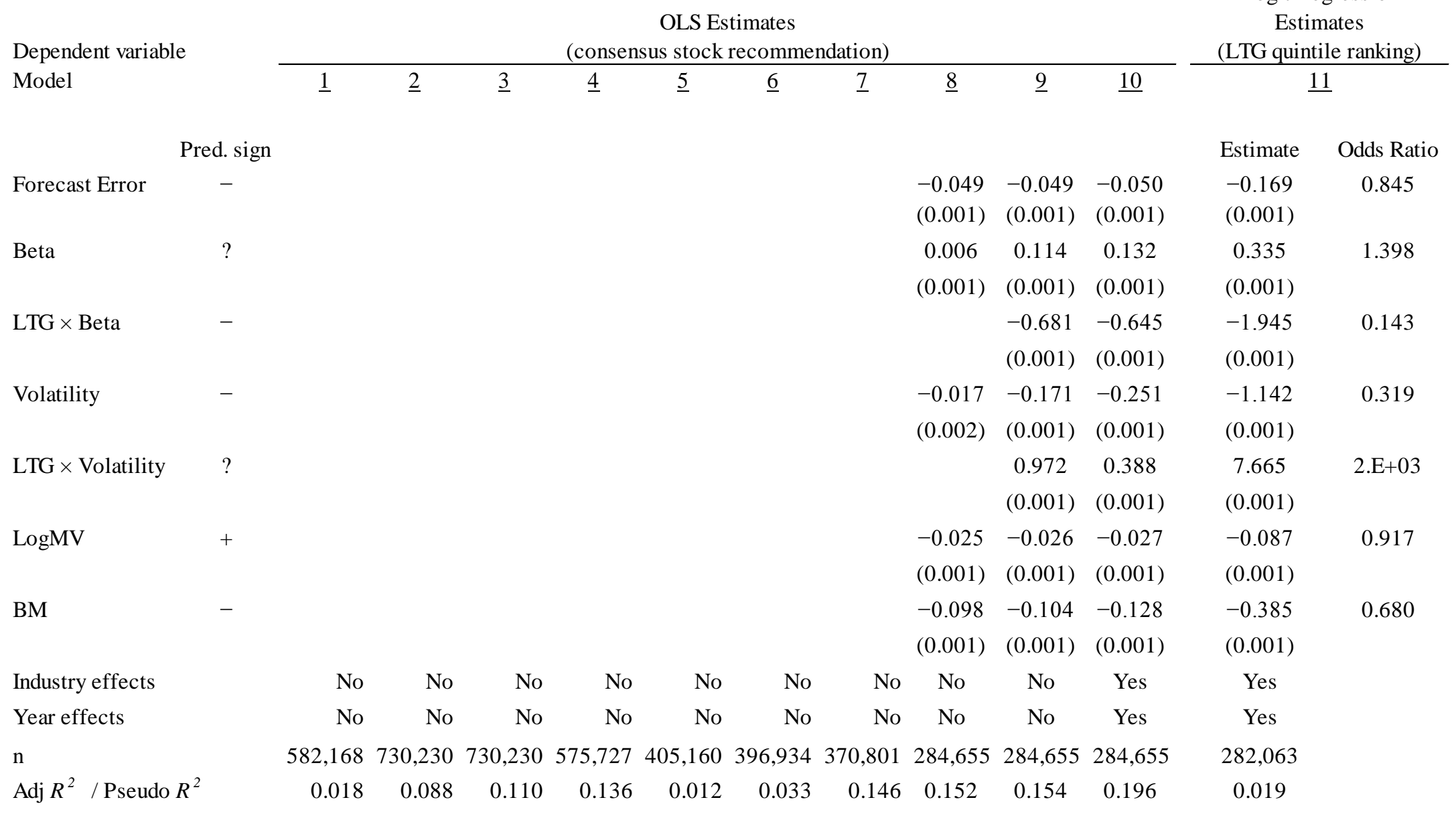


Table 4 (continued)

Panel B:

$R E C=\alpha_{0}+\beta_{1} S G+\beta_{2} L T G+\beta_{3} L T G_{-} Q^{1}+\beta_{4} L T G \times L T G_{-} Q^{1}+\beta_{5} L T G_{-} Q^{4}+\beta_{6} L T G \times L T G_{-} Q^{4}+\beta_{7} N D F E+\beta_{8} P D F E+\beta_{9} S N D F E+\beta_{10} S P D F E$

$+\beta_{11}$ Forecast Error $+\gamma_{1}$ Beta $+\gamma_{2} L T G \times$ Beta $+\gamma_{3}$ Volatility $+\gamma_{4} L T G \times$ Volatility $+\gamma_{5} \log M V+\gamma_{6} B M+\sum_{j=1}^{9} \delta_{j}$ Industry Dummy $+\sum_{i=1995}^{2012} \theta_{i}$ Yr Dummy $+\varepsilon$

Dependent variable: Consensus stock recommendation

\begin{tabular}{|c|c|c|c|c|c|c|c|c|c|c|}
\hline \multirow[b]{2}{*}{ Model } & \multirow[b]{2}{*}{ Pred. sign } & \multicolumn{5}{|c|}{ Full Sample Period: 1995-2012 } & \multicolumn{2}{|c|}{ Period: 1995-2006 } & \multicolumn{2}{|c|}{ Period: 2007-2012 } \\
\hline & & $\underline{1}$ & $\underline{2}$ & $\underline{3}$ & $\underline{4}$ & $\underline{5}$ & $\underline{6}$ & $\underline{7}$ & $\underline{8}$ & $\underline{9}$ \\
\hline Intercept & + & $\begin{array}{r}3.319 \\
(0.001)\end{array}$ & $\begin{array}{r}3.497 \\
(0.001)\end{array}$ & $\begin{array}{r}3.319 \\
(0.001)\end{array}$ & $\begin{array}{r}3.289 \\
(0.001)\end{array}$ & $\begin{array}{r}3.587 \\
(0.001)\end{array}$ & $\begin{array}{r}3.166 \\
(0.001)\end{array}$ & $\begin{array}{r}3.426 \\
(0.001)\end{array}$ & $\begin{array}{r}3.335 \\
(0.001)\end{array}$ & $\begin{array}{r}3.459 \\
(0.001)\end{array}$ \\
\hline SG & + & $\begin{array}{r}0.091 \\
(0.001)\end{array}$ & $\begin{array}{r}0.106 \\
(0.001)\end{array}$ & $\begin{array}{r}0.092 \\
(0.001)\end{array}$ & $\begin{array}{r}0.118 \\
(0.001)\end{array}$ & $\begin{array}{r}0.107 \\
(0.001)\end{array}$ & $\begin{array}{r}0.104 \\
(0.001)\end{array}$ & $\begin{array}{r}0.101 \\
(0.001)\end{array}$ & $\begin{array}{r}0.109 \\
(0.001)\end{array}$ & $\begin{array}{r}0.117 \\
(0.001)\end{array}$ \\
\hline LTG & + & $\begin{array}{r}3.217 \\
(0.001)\end{array}$ & $\begin{array}{r}3.420 \\
(0.001)\end{array}$ & $\begin{array}{r}3.216 \\
(0.001)\end{array}$ & $\begin{array}{r}3.447 \\
(0.001)\end{array}$ & $\begin{array}{r}3.134 \\
(0.001)\end{array}$ & $\begin{array}{r}4.246 \\
(0.001)\end{array}$ & $\begin{array}{r}4.254 \\
(0.001)\end{array}$ & $\begin{array}{r}2.850 \\
(0.001)\end{array}$ & $\begin{array}{r}2.941 \\
(0.001)\end{array}$ \\
\hline LTG_Q ${ }^{1}$ & - & $\begin{array}{l}-0.023 \\
(0.001)\end{array}$ & $\begin{array}{l}-0.042 \\
(0.001)\end{array}$ & $\begin{array}{l}-0.136 \\
(0.001)\end{array}$ & $\begin{array}{l}-0.110 \\
(0.001)\end{array}$ & $\begin{array}{l}-0.230 \\
(0.001)\end{array}$ & $\begin{array}{l}-0.083 \\
(0.001)\end{array}$ & $\begin{array}{l}-0.068 \\
(0.001)\end{array}$ & $\begin{array}{r}0.081 \\
(0.001)\end{array}$ & $\begin{array}{r}0.092 \\
(0.001)\end{array}$ \\
\hline LTG_Q1 × POSTY06 & ? & & & $\begin{array}{r}0.261 \\
(0.001)\end{array}$ & $\begin{array}{r}0.254 \\
(0.001)\end{array}$ & $\begin{array}{r}0.306 \\
(0.001)\end{array}$ & & & & \\
\hline $\mathrm{LTG} \times$ LTG_Q ${ }^{1}$ & + & $\begin{array}{l}-0.496 \\
(0.001)\end{array}$ & $\begin{array}{l}-0.291 \\
(0.001)\end{array}$ & $\begin{array}{r}0.668 \\
(0.001)\end{array}$ & $\begin{array}{r}0.360 \\
(0.001)\end{array}$ & $\begin{array}{r}1.169 \\
(0.001)\end{array}$ & $\begin{array}{r}0.976 \\
(0.001)\end{array}$ & $\begin{array}{r}0.819 \\
(0.001)\end{array}$ & $\begin{array}{l}-1.838 \\
(0.001)\end{array}$ & $\begin{array}{l}-1.726 \\
(0.001)\end{array}$ \\
\hline LTG $\times$ LTG_Q ${ }^{1} \times$ POSTY06 & ? & & & $\begin{array}{l}-2.706 \\
(0.001)\end{array}$ & $\begin{array}{l}-2.669 \\
(0.001)\end{array}$ & $\begin{array}{l}-2.081 \\
(0.001)\end{array}$ & & & & \\
\hline LTG_Q ${ }^{4}$ & + & $\begin{array}{r}0.614 \\
(0.001)\end{array}$ & $\begin{array}{r}0.595 \\
(0.001)\end{array}$ & $\begin{array}{r}0.614 \\
(0.001)\end{array}$ & $\begin{array}{r}0.699 \\
(0.001)\end{array}$ & $\begin{array}{r}0.565 \\
(0.001)\end{array}$ & $\begin{array}{r}0.663 \\
(0.001)\end{array}$ & $\begin{array}{r}0.580 \\
(0.001)\end{array}$ & $\begin{array}{r}0.521 \\
(0.001)\end{array}$ & $\begin{array}{r}0.452 \\
(0.001)\end{array}$ \\
\hline $\mathrm{LTG} \times \mathrm{LTG} \_\mathrm{Q}^{4}$ & - & $\begin{array}{l}-2.848 \\
(0.001)\end{array}$ & $\begin{array}{l}-2.811 \\
(0.001)\end{array}$ & $\begin{array}{l}-2.848 \\
(0.001)\end{array}$ & $\begin{array}{l}-3.258 \\
(0.001)\end{array}$ & $\begin{array}{l}-2.618 \\
(0.001)\end{array}$ & $\begin{array}{l}-3.565 \\
(0.001)\end{array}$ & $\begin{array}{l}-3.159 \\
(0.001)\end{array}$ & $\begin{array}{l}-2.810 \\
(0.001)\end{array}$ & $\begin{array}{l}-2.434 \\
(0.001)\end{array}$ \\
\hline
\end{tabular}


Panel B: (continued)

\begin{tabular}{|c|c|c|c|c|c|c|c|c|c|c|}
\hline \multirow[b]{2}{*}{ Model } & \multirow[b]{2}{*}{ Pred. sign } & \multicolumn{5}{|c|}{ Full Sample Period: 1995-2012 } & \multicolumn{2}{|c|}{ Period: 1995-2006 } & \multicolumn{2}{|c|}{ Period: 2007-2012 } \\
\hline & & $\underline{1}$ & $\underline{2}$ & $\underline{3}$ & $\underline{4}$ & $\underline{5}$ & $\underline{6}$ & $\underline{7}$ & $\underline{8}$ & $\underline{9}$ \\
\hline \multirow[t]{2}{*}{ NDFE } & + & & 0.241 & & 0.588 & 0.439 & & -0.316 & & 2.037 \\
\hline & & & $(0.001)$ & & $(0.001)$ & $(0.001)$ & & $(0.009)$ & & $(0.001)$ \\
\hline \multirow[t]{2}{*}{ PDFE } & + & & 0.703 & & 1.018 & 0.752 & & 1.289 & & 0.472 \\
\hline & & & $(0.001)$ & & $(0.001)$ & $(0.001)$ & & $(0.001)$ & & $(0.001)$ \\
\hline \multirow{2}{*}{ SNDFE } & + & & 1.959 & & 7.718 & 3.050 & & 2.225 & & 10.284 \\
\hline & & & $(0.001)$ & & $(0.001)$ & $(0.001)$ & & $(0.001)$ & & $(0.001)$ \\
\hline \multirow[t]{2}{*}{ SPDFE } & - & & -3.525 & & -3.960 & -3.567 & & -5.775 & & -2.926 \\
\hline & & & $(0.001)$ & & $(0.001)$ & $(0.001)$ & & $(0.001)$ & & $(0.001)$ \\
\hline \multirow[t]{2}{*}{ Forecast Error } & - & & -0.003 & & -0.045 & -0.053 & & -0.054 & & -0.041 \\
\hline & & & $(0.001)$ & & $(0.001)$ & $(0.001)$ & & $(0.001)$ & & $(0.001)$ \\
\hline \multirow[t]{2}{*}{ Beta } & $?$ & & 0.110 & & & 0.113 & & 0.049 & & 0.139 \\
\hline & & & $(0.001)$ & & & $(0.001)$ & & $(0.001)$ & & $(0.001)$ \\
\hline \multirow[t]{2}{*}{ LTG $\times$ Beta } & - & & -0.555 & & & -0.543 & & -0.431 & & -0.627 \\
\hline & & & $(0.001)$ & & & $(0.001)$ & & $(0.001)$ & & $(0.001)$ \\
\hline \multirow[t]{2}{*}{ Volatility } & - & & -0.292 & & & -0.278 & & -0.007 & & -0.230 \\
\hline & & & $(0.001)$ & & & $(0.001)$ & & $(0.001)$ & & $(0.001)$ \\
\hline \multirow[t]{2}{*}{ LTG $\times$ Volatility } & $?$ & & 0.552 & & & 0.680 & & 0.226 & & 1.178 \\
\hline & & & $(0.001)$ & & & $(0.001)$ & & $(0.001)$ & & $(0.001)$ \\
\hline \multirow[t]{2}{*}{ LogMV } & + & & -0.026 & & & -0.025 & & -0.030 & & -0.013 \\
\hline & & & $(0.001)$ & & & $(0.001)$ & & $(0.001)$ & & $(0.001)$ \\
\hline \multirow[t]{2}{*}{ BM } & $?$ & & -0.136 & & & -0.104 & & -0.139 & & -0.048 \\
\hline & & & $(0.001)$ & & & $(0.001)$ & & $(0.001)$ & & $(0.001)$ \\
\hline Industry effects & & No & Yes & No & No & Yes & & No & & No \\
\hline Year effects & & No & Yes & No & No & Yes & & No & & No \\
\hline $\mathrm{n}$ & & 575,727 & 291,834 & 575,727 & 370,909 & 284,655 & 188,677 & 186,482 & 96,687 & 95,581 \\
\hline Adj $R^{2}$ & & 0.137 & 0.194 & 0.138 & 0.156 & 0.197 & 0.168 & 0.179 & 0.097 & 0.116 \\
\hline
\end{tabular}

Panel A of the table presents the coefficient estimates and $p$-values (in parentheses) of equation (6a). The sample period is January 1995-December 2012. Models 1-10 of the panel report the results of the OLS regression tests that employ monthly consensus stock recommendation as the dependent variable. $R E C$ can be any value between 1 and 5, with the favourableness increasing from "strong sell” to "strong buy". Model 11 reports the estimates of the Ordered Multinomial regression 
analysis that employs the quintile ranking of consensus stock recommendation as the dependent variable. Panel B of the table presents the coefficient estimates and $p$-values (in parentheses) of equation (6b). Following Petersen (2009), we adjust the standard errors of the regression slopes in the regression tests of the table for the possible dependence in residuals by clustering standard errors on firm and month dimensions. $L T G^{2}$, square value of $L T G$; $S N D F E$, the square of $D F E$ when $D F E$ is negative and 0 otherwise; $S P D F E$, the square of $D F E$ when $D F E$ is positive and 0 otherwise; $L T G \_Q^{1}$, indicator variable taking the value of 1 when the LTG forecast falls into the $1^{\text {st }}$ (low) quartile of LTG, and 0 otherwise; $L T G Q^{4}$, indicator variable taking the value of 1 when the LTG forecast falls into the $4^{\text {th }}$ (high) quartile of LTG, and 0 otherwise; $L T G \times L T G \_Q^{1}$, interaction variable between $L T G$ and the indicator variable $L T G \_Q^{1}$; $L T G \times L T G \_Q^{4}$, interaction variable between $L T G$ and the indicator variable $L T G_{-} Q^{4}$; Industry effects, vector of industry indicator variables based on the GICS level-1 classification; Year effects, vector of calendar year indicator variables. POSTY06, indicator variable taking the value of 1 when the consensus recommendation is estimated after December 2006, and 0 otherwise. LTG $\times L T G \_Q^{1} \times$ POSTY06, interaction variable between LTG $\times$ LTG_Q ${ }^{1}$ and POSTY06. See also Table 2 for variable definitions. 
Table 5

Relationship between stock recommendation profitability and analyst incorporation of the really long-term growth and risk

Panel A: RLTG and stock recommendation profitability

$$
\begin{aligned}
\text { CAR }_{(t, t+s)}= & \alpha+\beta_{1} A N Y S T \_R L T G+\beta_{2} \text { LogBSize }+\beta_{3} N_{-} \text {FIRM }+\beta_{4} N_{-} \text {IND } \\
& +\beta_{5} F R E Q^{E P S}+\beta_{6} A C C U R+\beta_{7} \text { FIRM }{ }_{-} E X P+\beta_{8} N_{-} \text {ANYST }+\beta_{9} L O S S \\
& +\beta_{10} B M+\beta_{11} \text { LogMV }+ \text { Industry effects }+ \text { Year effects }+\varepsilon
\end{aligned}
$$

\begin{tabular}{|c|c|c|c|c|c|c|}
\hline \multirow{2}{*}{$\begin{array}{l}\text { Dependent variable } \\
\text { Model }\end{array}$} & \multicolumn{3}{|c|}{ Size-Adj. Abnormal Returns } & \multicolumn{3}{|c|}{ Std Deviation-Adj. Abnormal Returns } \\
\hline & $\underline{1}$ & $\underline{2}$ & $\underline{3}$ & $\underline{4}$ & $\underline{5}$ & $\underline{6}$ \\
\hline & 3-day & 1-month & 12-month & 3-day & 1-month & 12-month \\
\hline \multirow[t]{2}{*}{ Intercept } & 0.033 & 0.049 & 0.129 & 0.040 & 0.054 & 0.043 \\
\hline & $(<.001)$ & $(<.001)$ & $(<.001)$ & $(<.001)$ & $(<.001)$ & $(0.015)$ \\
\hline \multirow[t]{2}{*}{ ANYST_RLTG } & 0.002 & 0.002 & 0.007 & 0.002 & 0.003 & 0.006 \\
\hline & $(0.001)$ & $(0.004)$ & $(0.078)$ & $(0.001)$ & $(0.006)$ & $(0.100)$ \\
\hline \multirow[t]{2}{*}{ LogBSIZE } & 0.000 & 0.000 & -0.005 & 0.000 & 0.000 & 0.002 \\
\hline & $(0.161)$ & $(0.542)$ & $(0.001)$ & $(0.099)$ & $(0.386)$ & $(0.319)$ \\
\hline \multirow[t]{2}{*}{ N_FIRM } & 0.000 & 0.000 & 0.000 & 0.000 & 0.000 & 0.000 \\
\hline & $(0.014)$ & $(0.865)$ & $(0.820)$ & $(0.034)$ & $(0.833)$ & $(0.141)$ \\
\hline \multirow[t]{2}{*}{ N_IND } & -0.001 & -0.001 & -0.002 & -0.001 & -0.001 & -0.003 \\
\hline & $(<.001)$ & $(0.001)$ & $(0.072)$ & $(<.001)$ & $(<.001)$ & $(0.001)$ \\
\hline \multirow[t]{2}{*}{ FREQ $^{\text {EPS }}$} & 0.001 & 0.001 & 0.001 & 0.001 & 0.001 & 0.002 \\
\hline & $(<.001)$ & $(<.001)$ & $(0.079)$ & $(<.001)$ & $(<.001)$ & $(0.001)$ \\
\hline \multirow[t]{2}{*}{ ACCUR } & 0.003 & 0.004 & -0.016 & 0.007 & 0.005 & 0.008 \\
\hline & $(<.001)$ & $(0.004)$ & $(0.029)$ & $(<.001)$ & $(0.001)$ & $(0.221)$ \\
\hline \multirow{2}{*}{ FIRM_EXP } & 0.000 & 0.000 & 0.002 & 0.000 & 0.000 & 0.001 \\
\hline & $(<.001)$ & $(<.001)$ & $(<.001)$ & $(0.006)$ & $(<.001)$ & $(<.001)$ \\
\hline \multirow[t]{2}{*}{ N_ANYST } & 0.000 & 0.000 & 0.000 & 0.000 & 0.000 & 0.001 \\
\hline & (0.129) & $(0.578)$ & $(0.322)$ & $(0.006)$ & $(0.492)$ & $(0.026)$ \\
\hline \multirow[t]{2}{*}{ LOSS } & 0.001 & 0.003 & -0.022 & 0.002 & 0.004 & -0.003 \\
\hline & $(0.106)$ & $(0.003)$ & $(0.002)$ & $(0.004)$ & $(0.002)$ & $(0.666)$ \\
\hline \multirow[t]{2}{*}{$\mathrm{BM}$} & 0.000 & 0.002 & 0.017 & -0.001 & 0.003 & 0.039 \\
\hline & $(0.748)$ & $(0.124)$ & $(0.011)$ & $(0.279)$ & $(0.059)$ & $(<.001)$ \\
\hline \multirow[t]{2}{*}{ LOGMV } & -0.004 & -0.006 & -0.013 & -0.005 & -0.006 & -0.011 \\
\hline & $(<.001)$ & $(<.001)$ & $(<.001)$ & $(<.001)$ & $(<.001)$ & $(<.001)$ \\
\hline Year effects & yes & yes & yes & yes & yes & yes \\
\hline Industry effects & yes & yes & yes & yes & yes & yes \\
\hline $\mathrm{n}$ & 141,473 & 146,984 & 147,540 & 149,569 & 151,116 & 149,350 \\
\hline Adj $R^{2}$ & 0.0230 & 0.011 & 0.005 & 0.020 & 0.010 & 0.005 \\
\hline
\end{tabular}


Table 5 (continued)

Panel B: RLTG, risk, and stock recommendation profitability

$$
\begin{aligned}
\text { CAR }_{(t, t+s)}= & \alpha+\beta_{1} \text { ANYST }-R L T G V O L+\beta_{2} \text { LogBSize }+\beta_{3} N_{-} \text {FIRM }+\beta_{4} N_{-} \text {IND } \\
& +\beta_{5} \text { FREQ }{ }^{E P S}+\beta_{6} \text { ACCUR }+\beta_{7} \text { FIRM }-E X P+\beta_{8} N_{-} \text {ANYST }+\beta_{9} L O S S \\
& +\beta_{10} B M+\beta_{11} \text { LogMV }+ \text { Industry effects }+ \text { Year effects }+\varepsilon
\end{aligned}
$$

\begin{tabular}{|c|c|c|c|c|c|c|}
\hline \multirow{2}{*}{$\begin{array}{l}\text { Dependent variable } \\
\text { Model }\end{array}$} & \multicolumn{3}{|c|}{ Size-Adj. Abnormal Returns } & \multicolumn{3}{|c|}{ Std Deviation-Adj. Abnormal Returns } \\
\hline & 1 & 2 & 3 & 4 & 5 & 6 \\
\hline & 3-day & 1-month & 12-month & 3-day & 1-month & 12-month \\
\hline \multirow[t]{2}{*}{ Intercept } & 0.034 & 0.050 & 0.112 & 0.043 & 0.050 & 0.044 \\
\hline & $(<.001)$ & $(<.001)$ & $(<.001)$ & $(<.001)$ & $(<.001)$ & $(0.012)$ \\
\hline \multirow[t]{2}{*}{ ANYST_RLTGVOL } & 0.001 & 0.001 & 0.002 & 0.001 & 0.001 & 0.007 \\
\hline & $(0.071)$ & $(0.146)$ & $(0.545)$ & $(0.078)$ & $(0.103)$ & $(0.044)$ \\
\hline \multirow[t]{2}{*}{ LogBSIZE } & 0.000 & 0.000 & 0.000 & 0.001 & 0.000 & 0.002 \\
\hline & $(0.103)$ & $(0.423)$ & $(0.886)$ & $(0.091)$ & $(0.175)$ & $(0.280)$ \\
\hline \multirow[t]{2}{*}{ N_FIRM } & 0.000 & 0.000 & 0.000 & 0.000 & 0.000 & 0.000 \\
\hline & $(0.009)$ & $(0.900)$ & $(0.421)$ & $(0.032)$ & $(0.863)$ & $(0.122)$ \\
\hline \multirow[t]{2}{*}{ N_IND } & -0.001 & -0.001 & -0.002 & -0.001 & -0.001 & -0.003 \\
\hline & $(<.001)$ & $(0.001)$ & $(0.024)$ & $(<.001)$ & $(<.001)$ & (0.001) \\
\hline \multirow[t]{2}{*}{ FREQ $^{\text {EPS }}$} & 0.001 & 0.001 & 0.002 & 0.001 & 0.001 & 0.002 \\
\hline & $(<.001)$ & $(<.001)$ & $(<.001)$ & $(<.001)$ & $(<.001)$ & $(0.001)$ \\
\hline \multirow[t]{2}{*}{ ACCUR } & 0.003 & 0.000 & 0.001 & 0.000 & 0.000 & 0.008 \\
\hline & $(<.001)$ & $(0.646)$ & $(0.093)$ & (0.194) & $(0.412)$ & $(0.222)$ \\
\hline \multirow[t]{2}{*}{ FIRM_EXP } & 0.000 & 0.000 & 0.002 & 0.000 & 0.000 & 0.001 \\
\hline & $(<.001)$ & $(<.001)$ & $(<.001)$ & $(0.017)$ & $(<.001)$ & $(<.001)$ \\
\hline \multirow[t]{2}{*}{ N_ANYST } & 0.000 & 0.000 & 0.001 & 0.000 & 0.000 & 0.001 \\
\hline & $(0.143)$ & $(0.577)$ & $(0.001)$ & $(0.006)$ & $(0.303)$ & $(0.026)$ \\
\hline \multirow[t]{2}{*}{ LOSS } & 0.001 & 0.004 & 0.005 & 0.003 & 0.005 & -0.003 \\
\hline & $(0.101)$ & $(0.004)$ & $(0.204)$ & (0.003) & $(<.001)$ & $(0.667)$ \\
\hline \multirow[t]{2}{*}{$\mathrm{BM}$} & 0.000 & 0.002 & 0.022 & -0.001 & 0.002 & 0.039 \\
\hline & $(0.739)$ & $(0.114)$ & $(<.001)$ & $(0.560)$ & $(0.077)$ & $(<.001)$ \\
\hline \multirow[t]{2}{*}{ LOGMV } & -0.004 & -0.006 & -0.015 & -0.005 & -0.006 & -0.011 \\
\hline & $(<.001)$ & $(<.001)$ & $(<.001)$ & $(<.001)$ & $(<.001)$ & $(<.001)$ \\
\hline Year effects & yes & yes & yes & yes & yes & yes \\
\hline Industry effects & yes & yes & yes & yes & yes & yes \\
\hline $\mathrm{n}$ & 141,473 & 148,193 & 144,856 & 150,850 & 149,775 & 149,350 \\
\hline $\operatorname{Adj} R^{2}$ & 0.0230 & 0.011 & 0.007 & 0.019 & 0.011 & 0.006 \\
\hline
\end{tabular}

This table reports the regression results of the relationships between the profitability of recommendations and analyst incorporation of RLTG and risk. Panel A reports the results of estimating Equation (9a). Panel B reports the results of estimating Equation (9b). ANYST_RLTG, 1 if the estimate of DFE in Equation (8) for an analyst is negative, and 0 otherwise; ANYST_RLTGVOL, 1 if the estimates of DFE and Volatility in Equation (9) for an analyst are both negative, and 0 otherwise; $R E C^{\text {individual }}$, stock recommendations issued 
by individual analysts on the I/B/E/S database; $C A R_{t-1, t+1}^{\text {Size-Adj }}$, size-adjusted cumulative abnormal stock return over the three trading days beginning on the day prior to the stock recommendation announcement day $t$. We calculate the size-adjusted returns by subtracting the appropriate CRSP market capitalization decile returns from the stock's raw returns; $C A R_{t, t+30}^{\text {Size-Adj }}$, size-adjusted cumulative abnormal stock return over the 30 days following the stock recommendation announcement day $t ; C A R_{t, t+365}^{\text {Size-Adj }}$, size-adjusted cumulative abnormal stock return over the 12 months following the recommendation announcement day $t$; $C A R_{t-1, t+1}^{S t d-A d j}$, standard deviation decile-adjusted cumulative abnormal stock return over the three days beginning on the trading day prior to the stock recommendation announcement day $t$. We calculate the standard deviation decile-adjusted abnormal returns by subtracting the appropriate CRSP standard deviation decile returns from the stock's raw returns; $C A R_{t, t+30}^{S t d-A d j}$, standard deviation decile-adjusted cumulative abnormal stock return over the 30 days following the stock recommendation announcement day $t$; $C A R_{t, t+365}^{S t d-A d j}$, standard deviation decile-adjusted cumulative abnormal stock return over the 12 months following the stock recommendation announcement day $t$; $N \_F I R M$, number of firms covered by an analyst in a given year; $N \_I N D$, number of industries covered by an analyst in a given year; LogBSIZE, nature log of the number of analysts employed by a brokerage firm in a given year; $B M$, book-to-market ratio; LogMV, nature log of the market capitalization of the last fiscal year; LOSS, 1 if the firm's earnings before extraordinary items is negative in the previous year, and 0 otherwise; $N \_A N Y S T$, number of analysts following a specific firm in a given year; FIRM_EXP, number of years the analyst issues stock recommendation for a specific firm; $F R E Q^{E P S}$, number of one-year-ahead earnings per share forecasts issued by an analyst for a given firm in a given year; ACCUR, accuracy of the analyst's earnings forecast, measured as the absolute value of the difference between the actual earnings and the analyst's last earnings forecast, deflated by the absolute value of the actual earnings. 